\title{
Brief communication: The role of using precipitation or river discharge data when assessing global coastal compound flooding
}

\author{
Emanuele Bevacqua $^{1, \text { o }}$, Michalis I. Vousdoukas ${ }^{2}$, Theodore G. Shepherd ${ }^{1}$, and Mathieu Vrac ${ }^{3}$ \\ ${ }^{1}$ Department of Meteorology, University of Reading, Reading, UK \\ ${ }^{2}$ Joint Research Centre (JRC), European Commission, Ispra, Italy \\ ${ }^{3}$ Laboratoire des Sciences du Climat et de l'Environnement, CNRS/IPSL, Gif-sur-Yvette, France \\ Invited contribution by Emanuele Bevacqua, recipient of the Outstanding Student Poster and PICO (OSPP) Award 2018.
}

Correspondence: Emanuele Bevacqua (e.bevacqua@ reading.ac.uk)

Received: 16 December 2019 - Discussion started: 9 January 2020

Revised: 11 May 2020 - Accepted: 14 May 2020 - Published: 17 June 2020

\begin{abstract}
Interacting storm surges and high water runoff can cause compound flooding $(\mathrm{CF})$ in low-lying coasts and river estuaries. The large-scale CF hazard has been typically studied using proxies such as the concurrence of storm surge extremes either with precipitation or with river discharge extremes. Here the impact of the choice of such proxies is addressed employing state-of-the-art global datasets. Although they are proxies of diverse physical mechanisms, we find that the two approaches show similar CF spatial patterns. On average, deviations are smaller in regions where assessing the actual $\mathrm{CF}$ is more relevant, i.e. where the $\mathrm{CF}$ potential is high. Differences between the two assessments increase with the catchment size, and our findings indicate that $\mathrm{CF}$ in long rivers (catchment $\gtrsim 5-10 \times 10^{3} \mathrm{~km}^{2}$ ) should be analysed using river discharge data. The precipitation-based assessment allows for considering local-rainfall-driven $\mathrm{CF}$ and $\mathrm{CF}$ in small rivers not resolved by large-scale datasets.
\end{abstract}

\section{Introduction}

Compound flooding (CF) happens in low-lying coastal areas due to the interaction of high precipitation runoff and high sea level. The combination of the two hazards can cause larger damages than those caused by either of the hazards in isolation, and recent events have occurred in e.g. Mozambique (2019), Texas (USA, 2017), the Shoalhaven estuary (Australia, 2016), Ravenna (Italy, 2015), Cork (Ireland, 2009), and Lymington (UK, 1999) (Couasnon et al., 2020; Zscheischler et al., 2018; Kumbier et al., 2018; Bevacqua et al., 2017; Olbert et al., 2017; Hendry et al., 2019). Practitioners and the scientific community are becoming more aware of CF risk, and there were several recent studies addressing the phenomenon at local (Bevacqua et al., 2017; Kumbier et al., 2018; van den Hurk et al., 2015; Ridder et al., 2018) or larger scales (Wahl et al., 2015; Bevacqua et al., 2019; Couasnon et al., 2020; Ward et al., 2018; Ganguli and Merz, 2019a, b; Wu and Leonard, 2019; Wu et al., 2018; Moftakhari et al., 2017). Recent advances in large-scale sea level and river discharge modelling allowed for the generation of sub-daily time series of water levels along the global coastline (Vousdoukas et al., 2018; Muis et al., 2016), thus enabling continental CF assessments (Ward et al., 2018; Bevacqua et al., 2019; Couasnon et al., 2020).

$\mathrm{CF}$ can be the result of different mechanisms depending on the local topography and meteorology. According to Wahl et al. (2015), CF is possible to occur when (1) the joint occurrence of high river discharge and storm surge in estuarine regions may elevate water levels to a point where flooding is initiated or its impacts are exacerbated; (2) a destructive storm surge, which already caused widespread flooding, is followed by rainfall, as the latter can drive additional flooding, even if it is not an extreme event on its own; and (3) a moderate storm surge occurs which does not directly cause flooding but is high enough to fully block or slow down gravity-fed storm water drainage, and as a result precipitation causes flooding. In addition, CF may occur if (4) precipitation falls on wet soil that is saturated by a preceding storm surge (Bevacqua et al., 2019). 
Quantifying the actual CF, i.e. the water level resulting from the combination of pluvial or fluvial flooding and high sea level, is challenging. For example, quantifying and interpreting $\mathrm{CF}$ in the vicinity of rivers (mechanism 1 ) requires water level measurements in the river mouth, which are rare, probably because most gauges are installed to monitor either riverine or marine processes (Bevacqua et al., 2017; Paprotny et al., 2018). Model-based data are also limited because only recently have modellers started considering CF. Statistical and hydrodynamic modelling approaches integrating fluvial and sea level flooding have been developed and applied recently at the local scale (Bevacqua et al., 2017; van den Hurk et al., 2015; Kumbier et al., 2018; Khanal et al., 2019); however, at a large scale, these approaches are only now being developed. Similarly, the explicit study of the actual CF water level due to pluvial flooding and storm surges (mechanisms 2-4) has not received much attention so far, to our knowledge, which may also be due to the scarcity of data. Thus, to gain information on the CF hazard at the regional, continental, or global scales, scientists usually employ proxies of flood hazard, e.g. the probability of potential CF (Bevacqua et al., 2019; Ward et al., 2018; Wahl et al., 2015; Couasnon et al., 2020; Paprotny et al., 2018). Quantifying potential CF, under the present or future climate, is useful, as it allows for identifying potential hotspots of CF hazard. Then, more detailed assessments of the local CF risk can be carried out at such hotspots, using computationally intensive methodologies that integrate all the hydrological and meteorological sources of flooding and their physical interaction (Wahl et al., 2015).

The large-scale assessment of potential CF includes the analysis of the probability (or return periods) of concurring extreme values of $\mathrm{CF}$ drivers. Two main approaches exist, focussing, respectively, on the analysis of the probability of concurring high values of sea level and river discharge or of sea level and precipitation. Through considering river discharge, the first approach takes into account CF in estuaries and deltas, i.e. serving as a proxy of CF mechanism 1 . The second approach, based on the analysis of accumulated precipitation around the coast when the high sea levels occur, can represent $\mathrm{CF}$ due to local precipitation extremes, i.e. related to mechanisms 2,3 , and 4 . Given that precipitation is among the main drivers of river discharge, the two proxies are correlated to a certain extent, and the use of precipitation can thereby allow for quantifying CF potential also in certain river estuaries. However, the correlation between the two proxies can be sometimes poor, especially in locations where river discharge is strongly influenced by other factors such as snowmelt, evaporation, and accumulated precipitation over previous weeks or months (Blöschl et al., 2019).

Given the scarcity and heterogeneous distribution of in situ data (Ward et al., 2018; Couasnon et al., 2020; Wu et al., 2018), scientists have started to employ model data - of river discharge, storm surge, and precipitation - to assess the large-scale potential CF hazard (Ward et al., 2018; Bevac- qua et al., 2019; Wu et al., 2018; Couasnon et al., 2020; Wu et al., 2018; Paprotny et al., 2018; Bevacqua et al., 2020). Against the foregoing background, the present study aims to assess whether a precipitation-based large-scale CF assessment can be used as a surrogate for potential CF in estuaries at the large-scale. To that end we use coherent global model datasets of storms surges (including wave effects; Vousdoukas et al., 2018), precipitation (Beck et al., 2017b), and river discharge (Couasnon et al., 2020; Eilander, 2019) and conduct a first global comparison of the results obtained through the two approaches, keeping all the other methodological aspects identical.

\section{Data}

We analyse the period 1979-2015. We consider river discharge daily maxima from a publicly available global dataset (Eilander, 2019; Couasnon et al., 2020), which includes coastal catchments larger than $1000 \mathrm{~km}^{2}$. The dataset was the result of hydrological model simulations forced with temperature and potential evaporation derived from ERA-Interim (European Centre for Medium-Range Weather Forecasts Reanalysis) and with precipitation from the MSWEPv1.2 dataset (Multi-Source Weighted-Ensemble Precipitation; Couasnon et al., 2020). The latter is obtained by merging gauge, satellite, and reanalysis data (including ERA-Interim); more information can be found in Beck et al. (2017b).

Precipitation is taken from the same MSWEPv1.2 dataset used to simulated river discharges and consists of daily data over a $0.25^{\circ}$ grid. On each day we consider accumulated precipitation amounts within a $3 \mathrm{~d}$ centred window. This enables us to account for precipitation occurring just before and after midnight of the storm surge day (Bevacqua et al., 2019; Martius et al., 2016) and to consider different mechanisms causing CF (Wahl et al., 2015; Bevacqua et al., 2019).

Storm surges and waves were simulated with the hydrodynamic model D-Flow Flexible Mesh (D-Flow FM; Vousdoukas et al., 2017, 2018) and the wave model Wavewatch III (Mentaschi et al., 2017; Vousdoukas et al., 2017, 2018). The wave model was forced by 6-hourly wind, while D-Flow FM was also forced by sea level pressure fields, both available from the ERA-Interim reanalysis (Dee et al., 2011). The effects of tropical cyclones (TCs) were considered in the reanalysis through storm surge simulations forced by downscaled atmospheric fields from all recorded TCs and by considering satellite-observed TC wave extremes (Vousdoukas et al., 2018). Astronomical tides are not considered in this analysis in order to focus on the meteorological component of the sea level, excluding the stochastic coupling with tide induced water level variations. We consider daily water level maxima from the combined result of storm surges and wave setup (hereinafter mentioned as storm surges) according to Vousdoukas et al. (2018). 
We analyse CF only around river mouth locations whose nearest precipitation and storm surge grid points lie within a distance of $75 \mathrm{~km}$ (Couasnon et al., 2020). This results in considering locations at river mouths of catchments with a size of between about 1000 and $3690000 \mathrm{~km}^{2}$ (95\% having a size smaller than $50000 \mathrm{~km}^{2}$; Fig. 3f).

\subsection{Methods}

We assess the potential CF hazard via bivariate return periods of concurring extreme events (Vandenberghe et al., 2011; Manning et al., 2019) of the variables $X$ and $Y$, i.e. storm surge and precipitation $\left(\mathrm{CF}_{\text {prec }}\right)$ or storm surge and river discharge $\left(\mathrm{CF}_{\text {river }}\right)$. Extremes of the individual variables $\left(x_{\text {ext }}\right.$ and $\left.y_{\text {ext }}\right)$ are defined as the associated $\alpha$-year return levels. We use different $\alpha$ values in the following, though we present the main results for $\alpha=5$; images for $\alpha=2$ are shown in the Appendix. Return levels are obtained through fitting a generalised-extreme-value distribution to the annual maxima of the individual variables (Coles et al., 2001). Annual maxima are defined based on adjacent windows centred on the month where the climatological river discharge average is the highest, rather than from January-December windows (such a window definition reduces the chance of selecting two consecutive annual maxima belonging to the same river discharge extreme event and therefore leads to a more robust definition of the return levels). Overall, given the definition of the extremes based on $\alpha$-year return levels, the bivariate return period is inherently linked to the dependence of the pairs in the tail of the distribution.

CF bivariate return periods are computed following the methodology presented by Bevacqua et al. (2019). The CF return period computation is based on the bivariate distribution of the variables of interest ( $X$ and $Y$ ), which is estimated semi-empirically to allow for robust estimation. For a given location, we select pairs whose individual values are simultaneously larger than the individual 95th percentiles $\left(x_{\text {sel }}\right.$ and $y_{\text {sel }}$, and we model these pairs via a copula-based distribution. If the defined thresholds result in a small group of selected pairs, we lower the 95th percentile selection threshold to guarantee having at least 20 pairs. The choice of 20 pairs is a trade off between having a sufficient amount of selected pairs and employing a reasonably high threshold for the fit of extreme-value parametric distributions in the tail. Furthermore, the return periods are largely insensitive to changes in the threshold (results are similar based on 20, 30, and 40 pairs; not shown). The selection thresholds are generally high: $75 \%$ of the locations have a selected threshold larger than or equal to the 95th and 94th percentile for the precipitation- and river-based analysis, respectively. And $95 \%$ (99\%) of the locations have a selected threshold above the 93rd (88.5th) and 89th (85th) percentile for the precipitation- and river-based analysis, respectively.

Once pairs are selected, clusters of pairs separated by less than $3 \mathrm{~d}$ were considered as part of the same event repre- sented by the maximum $X$ and $Y$ values observed in the cluster. Note that while this choice has the drawback of not fully respecting the assumptions of independent realisations of the extreme events, which is necessary to apply extreme-value theory in its generic form, it allows for considering multiple storm surges that may occur during a sustained period of high river discharge and that could lead to multiple compound floods.

The return period is defined as

$$
\begin{aligned}
& T\left(x_{\mathrm{ext}}, y_{\mathrm{ext}}\right) \\
& =\frac{\mu}{P\left(\left(x>x_{\mathrm{ext}} \text { and } y>y_{\mathrm{ext}}\right) \mid\left(x>x_{\mathrm{sel}} \text { and } y>y_{\mathrm{sel}}\right)\right)} \\
& =\frac{\mu}{1-u_{X_{\mathrm{ext}}}-u_{Y_{\mathrm{ext}}}+C_{X Y}\left(u_{X_{\mathrm{ext}}}, u_{Y_{\mathrm{ext}}}\right)}
\end{aligned}
$$

where $\mu$ is the average time elapsing between the selected pairs, $u_{X_{\mathrm{ext}}}=F_{X}\left(x_{\mathrm{ext}}\right), F_{X}$ is the marginal cumulative distribution of the excesses over the selection threshold (accordingly for $Y$ ), and $C_{X Y}$ is the copula modelling the dependence between the selected pairs (see Fig. A1 for the dependence associated with the fitted copulas in the two assessments). Note that, as the return period is obtained as a combination of the average elapsing time $\mu$ and the parametric probability density function of the data in the tail, an exact correspondence between the dependence of the copula and the return period is not expected. We model the marginal distributions of $X$ and $Y$ beyond the selection thresholds by a generalised Pareto distribution (GPD). We fit copulas from the families Gaussian, $t$, Clayton, Gumbel, Frank, Joe, Clayton-Gumbel, Joe-Gumbel, Joe-Clayton, and Joe-Frank to the pair $\left(u_{X}, u_{Y}\right)$ (obtained via empirical marginal cumulative distribution function; Vandenberghe et al., 2011; Manning et al., 2018); then we select the best ranked family according to the Akaike information criterion. In general, the physical processes captured by the two assessments can differ (even at the same location); therefore we allow for the selection of different copulas in the two assessments. We fit copulas and marginal distributions via a maximum likelihood estimator ("VineCopula" $\mathrm{R}$ package of Schepsmeier et al., 2016; "ismev" R package of Heffernan et al., 2016). We test the goodness of fit of copulas and marginals via the Cramér-von Mises criterion ("eva" $\mathrm{R}$ package of Bader and Yan, 2016; VineCopula R package).

When referring to the assessment of whether the CF return periods based on river discharge $\left(T_{\text {river }}\right)$ are statistically different from those based on precipitation $\left(T_{\text {prec }}\right)$ or not, we use the concept of statistical compatibility, recently introduced by Amrhein et al. (2019). We compute the centred $95 \%(2.5 \%-97.5 \%)$ confidence interval of $T_{\text {prec }}$ on the basis of 600 resampled bivariate time series of precipitation and storm surge (each of them built randomly combining observed 1-calendar-year bivariate time series; Bevacqua et al., 2020). $T_{\text {river }}$ is regarded as being statistically compati- 
ble with $T_{\text {prec }}$ if $T_{\text {river }}$ lies within the $95 \%$ confidence interval of $T_{\text {prec }}$ and incompatible otherwise.

We qualitatively investigate how the two assessments compare for different classes of catchment size. To do so, we rank the rivers based on their catchment size and divide them into groups having the same sample size; for each group we compute different statistics to compare the two assessments: the Spearman correlation of $T_{\text {river }}$ and $T_{\text {prec }}$, the ratio of $T_{\text {river }} / T_{\text {prec }}$, and the percentage of locations with $T_{\text {river }}$ compatible to $T_{\text {prec }}$. This binning procedure provides equally robust statistics for each bin and shows similar results for small variations in the bin size.

\subsubsection{Results and discussion}

The spatial patterns of the potential CF return periods based on either precipitation $\left(T_{\text {prec }}\right)$ or river discharge $\left(T_{\text {river }}\right)$ are very similar (Fig. 1; Fig. A2 is identical but shows results based on extremes defined considering 2-year return levels). The results for clusters of locations with the $5 \%$ lowest CF return periods are also similar in the two assessments (Figs. A3 and A4). These hotspot regions are mainly found along the US, Central American, and southern North Atlantic coasts and in central Chile, Madagascar, and southern Japan.

While the spatial patterns of the CF return periods obtained from the two approaches are very similar, their relative differences can be substantial, especially at certain locations (Figs. 2 and A5). Given that the return period computation procedure involves several uncertainty factors (e.g. bivariate model fitting and the definition of the return levels), we test the hypothesis that the return period based on the river discharge is statistically compatible (at a $95 \%$ confidence level) with that based on precipitation. When defining extremes based on the 5-year return levels, the river-based return period is compatible with the precipitation-based value in about $82 \%$ of the locations (Fig. 2c; $76 \%$ for 2-year return levels; Fig. A5c). The spatial distribution of locations where $T_{\text {river }}$ is not statistically compatible with $T_{\text {prec }}$ does not seem to follow a clear spatial pattern, though it appears that $T_{\text {river }}$ is lower than $T_{\text {prec }}$ in northern Europe and in the tropics. The latter are areas where CF is unlikely. $T_{\text {river }}$ is higher than $T_{\text {prec }}$ along the Gulf of Mexico (Figs. 2c and A5c). Compatible $T_{\text {river }}$ and $T_{\text {prec }}$ values are found but with large discrepancies in the tropics and above $60^{\circ} \mathrm{N}$ (Fig. 2b), consistent with the high uncertainty of these large CF return periods that do not allow for detecting potential differences between $T_{\text {river }}$ and $T_{\text {prec. }}$.

In areas with a tendency towards high CF return periods, e.g. the tropics, neighbour locations show divergent values in the ratio between the return periods of the two assessments (dark-blue and red dots in Fig. 2). Further tests showed that this behaviour is not related to the goodness of fit of the bivariate distributions; rather it appears associated with the large uncertainties of high return periods and potentially with different catchment characteristics.
We find that there is a tendency towards higher differences in the two assessments at locations where either or both $T_{\text {prec }}$ and $T_{\text {river }}$ are high (i.e. where $T$ approaches the value expected under the independence of the CF drivers; Fig. A6). (This appears consistent with the high uncertainty associated with large CF return periods.) Such a finding has relevant implications, as it indicates that the two assessments tend to be similar, on average, where assessing the actual CF is more important, i.e. where there is a relatively high $\mathrm{CF}$ potential (Fig. A6).

The spatial association of the return period map obtained from the two assessments is shown in Figs. 3a and A7a. The Spearman correlation between $T_{\text {river }}$ and $T_{\text {prec }}$ is $\sim 0.7$ and increases as the return level threshold employed to define the extremes decreases, e.g. 0.66 and 0.73 for the 5- and 2-year return level, respectively (Figs. 3a and A7a). This trend in the correlation is consistent with the higher uncertainties characterising larger return periods.

Although some of the differences between the two assessments can be driven by uncertainties in the return period estimation, also several physical processes, e.g. topographydependent ones, may be involved. The Spearman correlation between the two assessments decreases $(p$ value $<0.0024)$ as the catchment size increases (Fig. 3c). The latter suggests that - for larger catchments - different processes may cause either positive or negative deviations between $T_{\text {river }}$ and $T_{\text {prec}}$.

Water levels in the mouth of small rivers are expected to be largely influenced by the precipitation around the coast (Hendry et al., 2019; van den Hurk et al., 2015; Bevacqua et al., 2017), while around large rivers, inland hydrological processes are usually dominant. Therefore, we qualitatively investigate whether the actual difference between the two assessments (quantified as $T_{\text {river }} / T_{\text {prec }}$ ) depends on the size of the catchment (Hendry et al., 2019). For example, the $T_{\text {river }} / T_{\text {prec }}$ ratio, defined using the 5-year return level, tends to increase with the catchment size (Fig. 3b; see the deviation of the scatterplot of $T_{\text {river }}$ vs. $T_{\text {prec }}$ from the identity line emerging with the increasing dimension of the catchment). For CF return periods defined based on 2-year return level extremes, the median $T_{\text {river }} / T_{\text {prec }}$ ratio is near unity for most of the catchments, even though the $T_{\text {river }} / T_{\text {prec }}$ ratio increases slightly for larger catchments (blue line in Fig. 3d). For higher return levels, the median $T_{\text {river }} / T_{\text {prec }}$ ratio increases with the size of the catchment (Fig. 3d), indicating that the $\mathrm{CF}$ assessments based on precipitation and river discharge differ largely for large rivers. For all return levels, the median $T_{\text {river }} / T_{\text {prec }}$ ratio is near unity for rivers whose catchment size is up to about $5-10 \times 10^{3} \mathrm{~km}^{2}$ (Fig. 3d), i.e. about $75 \%$ of the rivers presently analysed (Fig. 3f). Binning the rivers per catchment size, we find that the variance of the $T_{\text {river }} / T_{\text {prec }}$ ratio within each bin tends to be smaller for small rivers than for large rivers (Fig. 3d, shown by the dashed line for the 2year return level). However, it is important to highlight that there is substantial variance (Fig. 3d for the 2-year return level extremes), and that for a river of any catchment size 
(a) CF return periods based on precipitation $\left(T_{\text {prec }}\right)$
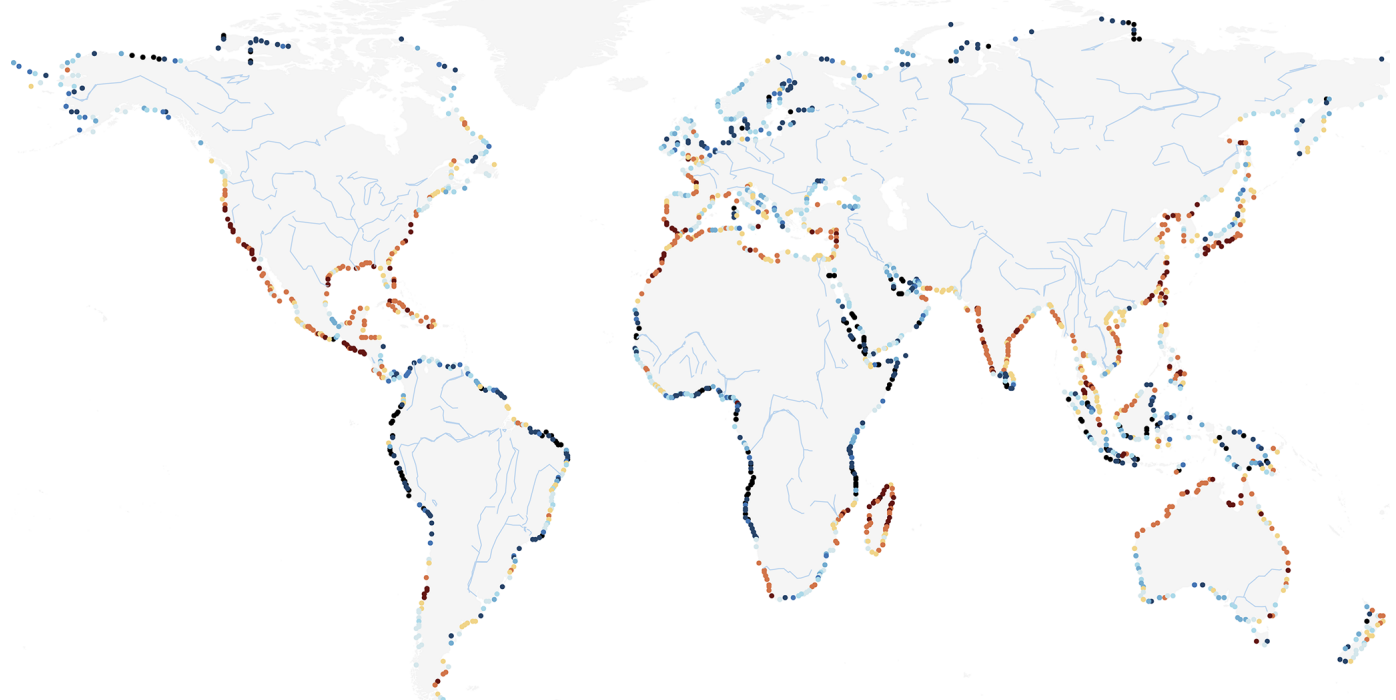

(b) CF return periods based on river discharges $\left(T_{\text {river }}\right)$
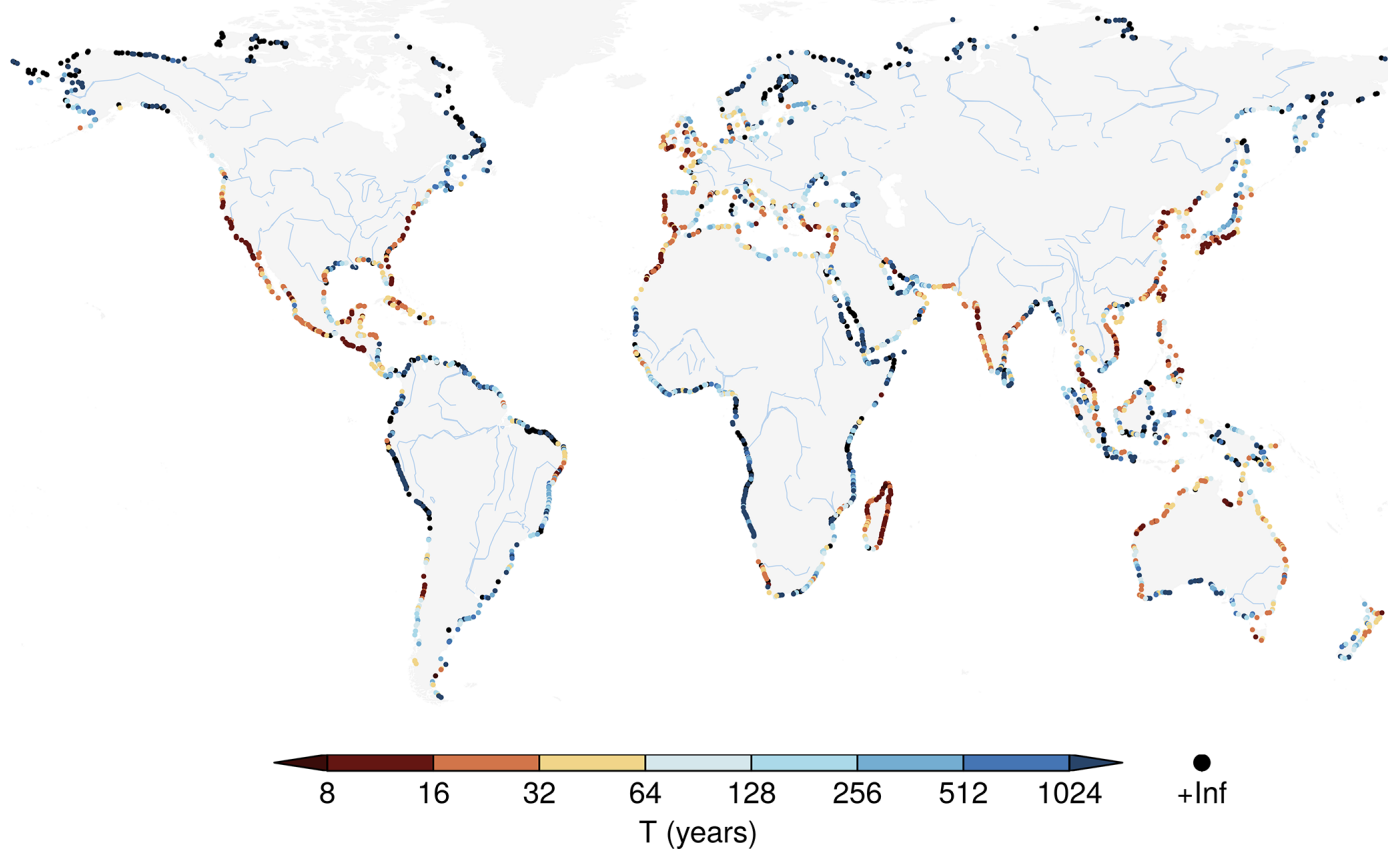

Figure 1. Present-day (1980-2014) potential compound-flooding probability based on precipitation and on river discharge. Return periods of CF defined as co-occurring extremes (5-year return levels) of the CF drivers. Return period of co-occurring (a) storm surge (including waves) and precipitation (accumulated $3 \mathrm{~d}$ centred) extremes and (b) storm surge (including waves) and river discharge extremes. Major rivers are shown in light blue. Infinite values are shown in black.

the associated $T_{\text {river }} / T_{\text {prec }}$ ratio can be either small or large. Overall, the similarity of $T_{\text {river }}$ and $T_{\text {prec }}$ for small rivers is highlighted by the fact that for small rivers it is more likely that $T_{\text {river }}$ is statistically compatible with $T_{\text {prec }}$ (Fig. 3e). For example, Fig. 3e (4-year return level curve) shows that $T_{\text {river }}$ is statistically compatible with $T_{\text {prec }}$ for $\sim 82 \%$ of the small rivers (catchment size $<5000 \mathrm{~km}^{2}$ ) and for $\sim 75 \%$ of large rivers (catchment size $>50000 \mathrm{~km}^{2}$ ). The decrease in the compatibility of $T_{\text {river }}$ and $T_{\text {prec }}$ with the catchment size (Fig. 3e) is statistically significant for return levels smaller than the 6-year return level ( $p$ value $<0.022$ ). However, for high return levels this decrease is not prominent, most likely 
(a) Ratio of CF return periods (statistically incompatible return periods)

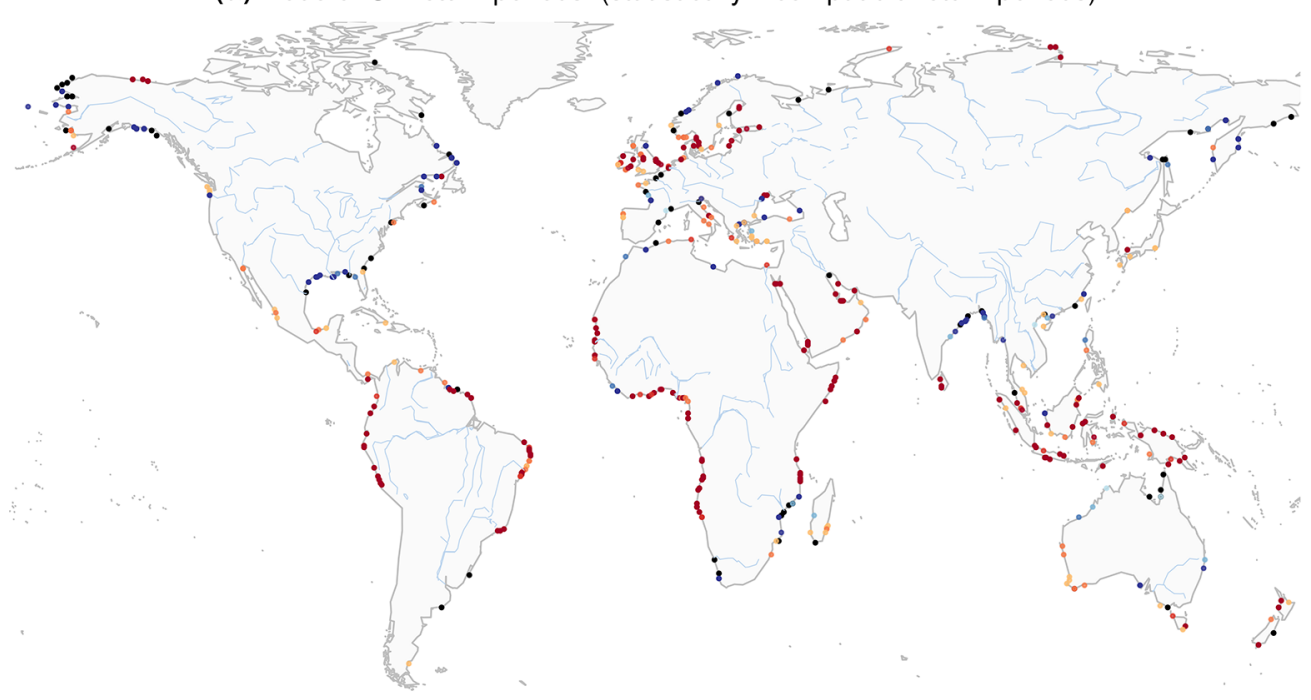

(b) Ratio of CF return periods (statistically compatible return periods)

(c)

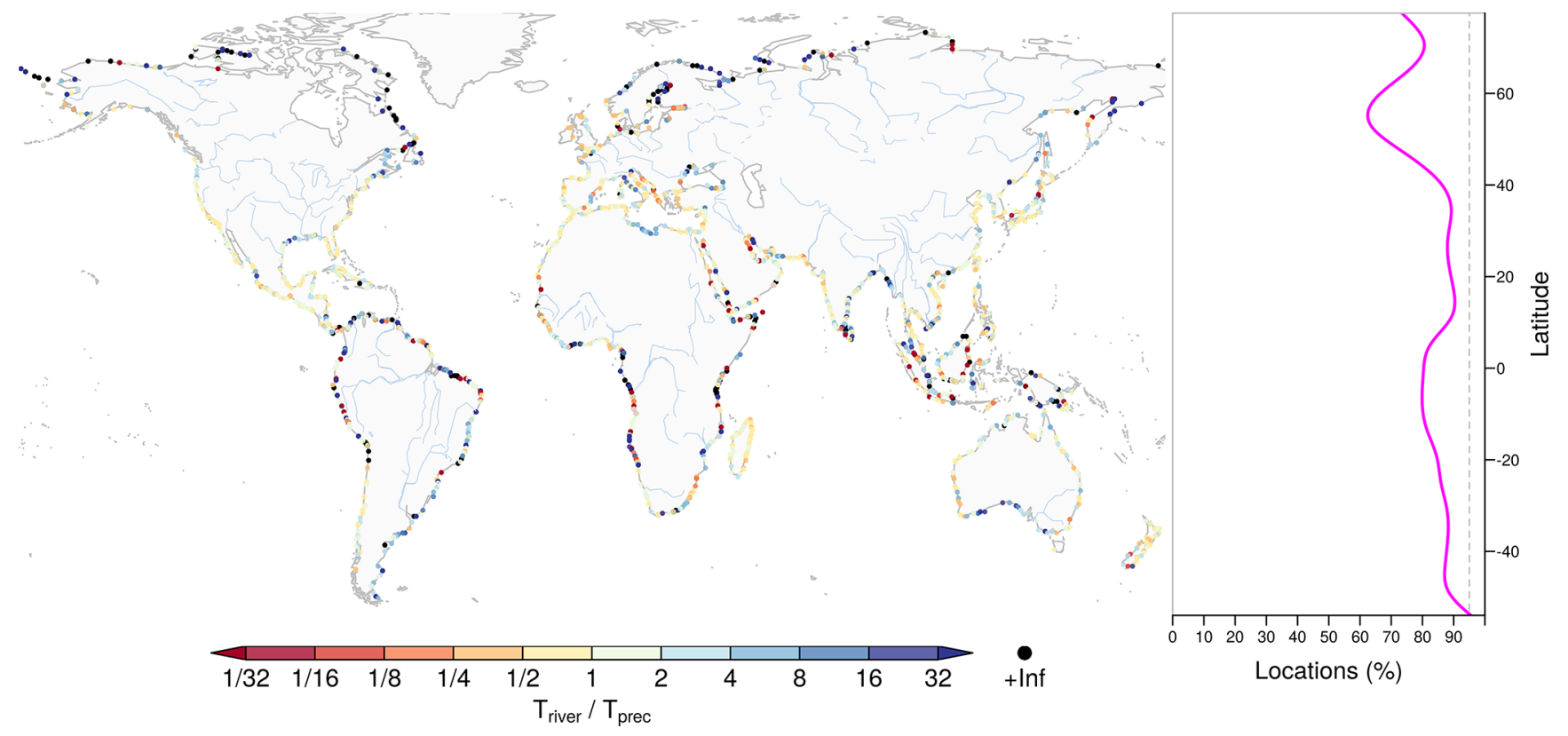

Figure 2. Difference between the present-day (1980-2014) potential compound-flooding probability based on precipitation and on river discharge. Ratio $\left(T_{\text {river }} / T_{\text {prec }}\right)$ of CF return period of concurring river discharge and storm surge extremes $\left(T_{\text {river }}\right)$ to CF return period of concurring precipitation (accumulated $3 \mathrm{~d}$ centred) and storm surge extremes $\left(T_{\text {prec }}\right)$. (a) The ratio where $T_{\text {river }}$ is statistically incompatible (at $95 \%$ confidence level; see Methods) with $T_{\text {prec. }}$ (b) The ratio where $T_{\text {river }}$ is statistically compatible with $T_{\text {prec }}$, while (c) shows the coastline fraction where this happens (binned every $5^{\circ}$ of latitude and smoothed using a spline function). In (c), the dashed grey line shows the $95 \%$ level.

due to the large uncertainty associated with longer return periods. Figure 3e indicates the discrepancy for large catchments in the $T_{\text {river }} / T_{\text {prec }}$ ratio being greater for low return levels, whereas Fig. $3 \mathrm{~d}$ indicates the opposite; this is also likely caused by the larger uncertainty of return periods of higher return levels, which does not allow for detecting potential differences between large values of $T_{\text {river }}$ and $T_{\text {prec }}$.
The differences between $T_{\text {river }}$ and $T_{\text {prec }}$ are not only controlled by the catchment size but can be the result of several other factors. During the hydrological modelling, input data artefacts or model inaccuracies, among other factors, introduce uncertainty which may contribute to the observed differences. Another important contribution should arise from the uncertainties in the bivariate return period estimation 

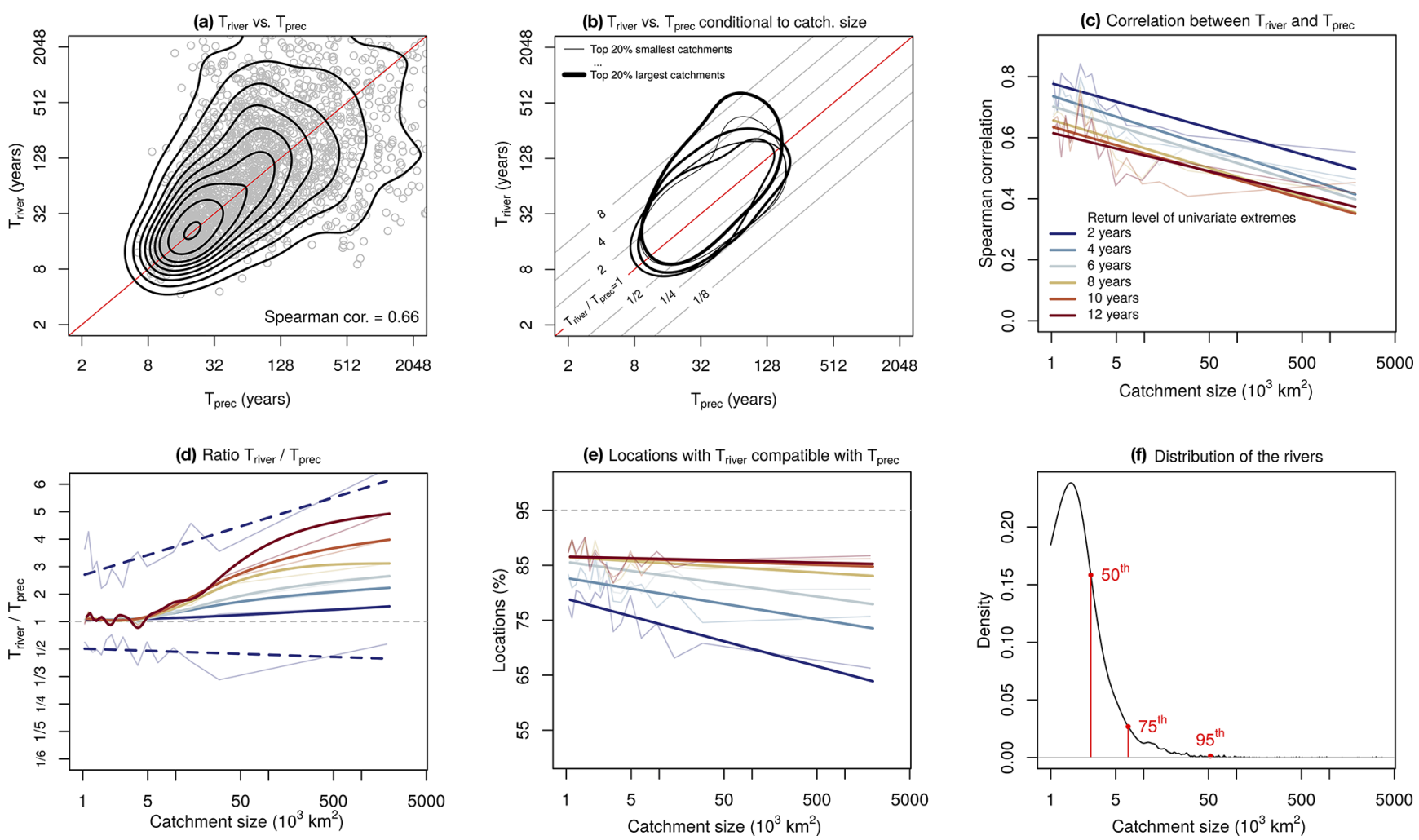

Figure 3. Comparison of the potential compound-flooding probability based on precipitation and on river discharge. (a) Scatterplot (based on Fig. A2) of CF return periods based on river discharge $\left(T_{\text {river }}\right)$ and on precipitation $\left(T_{\text {prec }}\right)$ for extremes defined based on 5-year return levels. Black contours represent the isolines of the kernel density containing from $10 \%$ to $90 \%$ of the $\left(T_{\text {river }}, T_{\text {prec }}\right)$ pairs. The identity line is shown in red. (b) Empirical probability density function of the variables ( $\left.T_{\text {river }}, T_{\text {prec }}\right)$ conditioned on the catchment size; the thickness of the isolines increases with the catchment size such that each bin considers one fifth of the total number of analysed rivers (3178). Each contour line (isolines of the kernel density) contains about $50 \%$ of the $\left(T_{\text {river }}, T_{\text {prec }}\right)$ pairs. (c-e) Statistics comparing $T_{\text {river }}$ and $T_{\text {prec }}$ as a function of the catchment size and of the return levels used to define the CF univariate extremes (see legend in a). (c) Spearman correlation between the maps of $T_{\text {river }}$ and $T_{\text {prec }}$. (d) $T_{\text {river }} / T_{\text {prec }}$ ratio. The dashed line is the centred $68 \%$ (16th-84th percentiles) confidence interval of the ratio based on the 2-year return levels. A non-linear $y$ axis for values below 1 is plotted such that the specular cases, e.g. ratio $r=2$ $\left(T_{\text {river }}=2 \cdot T_{\text {prec }}\right)$ and $r=1 / 2\left(T_{\text {prec }}=2 \cdot T_{\text {river }}\right)$ (see b), appear symmetric with respect to $r=1\left(T_{\text {river }}=T_{\text {prec }}\right)$. (To obtain the plot, the ratio is defined as $r=T_{\text {river }} / T_{\text {prec }}$; then if $r<1, r$ is transformed to $r=-T_{\text {prec }} / T_{\text {river }}+2$. Now e.g. $r=2$ and $r=0$ represent specular cases; therefore, where the $y$ axis is $r=0,1,2, \ldots$, we can write $r=1 / 2,1 / 3,1 / 4, \ldots)$ See Fig. A7b for the plot with a standard axis. (e) Percentage of locations where $T_{\text {river }}$ is statistically compatible with $T_{\text {prec }}$ at the $95 \%$ confidence level. (f) Probability density function of the catchment size of the analysed rivers; 50th, 75th, and 95th percentiles of the distribution are shown in red. In (c-e), thick lines are obtained through regressing the obtained statistical values per bin (thin lines) to the natural logarithm of the mean size of the catchment bins All lines are regressed using linear regression, except from the median of the ratio in (d), where a spline function is used. The slopes of the linear regressions are all significant in (c) $(p$ value $<0.0024)$ and significant up to the 6-year return level in (e) $(p$ value $<0.022)$.

(Bevacqua et al., 2019; Wahl et al., 2015), which can contribute to both positive and negative deviations between $T_{\text {river }}$ and $T_{\text {prec }}$. Moreover, the catchment response time to precipitation depends also on rock and soil catchment permeability (Hendry et al., 2019). Finally, river discharge is influenced not only by local coastal precipitation but also by the weather over the previous weeks or months over the catchment, including evaporation and potentially snowmelt (Couasnon et al., 2020; Bevacqua et al., 2017).

Clearly, the diversity of the physical processes leading to $\mathrm{CF}_{\text {prec }}$ and $\mathrm{CF}_{\text {river }}$ is very relevant and can cause both positive and negative differences between $T_{\text {river }}$ and $T_{\text {prec }}$
(Blöschl et al., 2019). For example, for any given catchment, a slow catchment response time may either increase or decrease the $T_{\text {river }} / T_{\text {prec }}$ ratio. In locations where cyclones cause frequent concurring storm surge and widespread coastal precipitation, it is not guaranteed that $\mathrm{CF}_{\text {river }}$ probability will be also high. For example, if the rainfall in the catchment upstream needs time to reach the coast long enough for the storm surge to recede, then $\mathrm{CF}_{\text {river }}$ will be unlikely, and in this case the $T_{\text {river }} / T_{\text {prec }}$ ratio will be high (Klerk et al., 2015; Ward et al., 2018). In contrast, where the $\mathrm{CF}_{\text {prec }}$ is unlikely because different weather systems cause precipitation and storm surge extremes, a relatively slow 
catchment response time may sometimes allow for high river discharge and storm surge to concur if e.g. a first cyclone causes precipitation driving high river discharge reaching the coast when a second cyclone drives a storm surge (contributing to a low $T_{\text {river }} / T_{\text {prec }}$ ratio; Bevacqua et al., 2019).

In addition the presence of a pronounced annual cycle in river discharge can modulate the river-discharge-driven CF hazard and thus the $T_{\text {river }} / T_{\text {prec }}$ ratio. In regions where $\mathrm{CF}_{\text {prec }}$ is likely, $\mathrm{CF}_{\text {river }}$ may be unlikely if the storm surge season does not coincide with the season of the high river discharge (high $T_{\text {river }} / T_{\text {prec }}$ ratio; Ward et al., 2018). In contrast, where the $\mathrm{CF}_{\text {prec }}$ is unlikely, $\mathrm{CF}_{\text {river }}$ may be more likely if the storm surge season coincides with the high-riverdischarge season (low $T_{\text {river }} / T_{\text {prec }}$ ratio). In addition, precipitation extremes are typically short in duration, while river discharge extremes are less dynamic. Although events exceeding the $\alpha$-year return level threshold occur both for precipitation and river discharge on average every $\alpha$ years, the number of days with high river discharge can be larger than the number of days with a high precipitation amount. From a statistical point of view, the above mechanism alone would make $\mathrm{CF}_{\text {river }}$ more likely than $\mathrm{CF}_{\text {prec }}$ (low $T_{\text {river }} / T_{\text {prec }}$ ratio; this effect is even more pronounced in catchments with a slow response time and especially in areas where different weather systems cause precipitation and storm surge extremes; Bevacqua et al., 2020). The above effect is weakened as the return level threshold used to define extremes increases due to the shorter duration of river discharge extremes. The above considerations justify the $T_{\text {river }} / T_{\text {prec }}$ ratio increasing with the return level choice (Fig. 3d).

While the relevance of the mechanisms discussed above may depend on the local climate, they are expected to be less relevant in very small rivers where the catchment response time is small, and thus autocorrelation in the river time series is smaller. Consistently, we find that $T_{\text {river }}$ and $T_{\text {prec }}$ tend to match more in smaller catchments. However, a higher agreement for small rivers might also arise from the relatively coarse spatial resolution of the data which would attenuate differences between precipitation and river discharges in small rivers. Overall, we find that independent of the catchment size, $T_{\text {river }}$ tends to be higher than $T_{\text {prec }}$ on average (Fig. 3d), suggesting that the mechanisms causing $T_{\text {river }}>T_{\text {prec }}$ may be more likely or relevant. Apparently this is a general remark and not a universal law, since there are also several locations where $T_{\text {prec }}$ exceeds $T_{\text {river }}$.

The presented results are based on state-of-the-art model data which have been validated and discussed in previous papers (Vousdoukas et al., 2018; Beck et al., 2017a; Couasnon et al., 2020; Bevacqua et al., 2019; Muis et al., 2016). However, the above-mentioned validation efforts did not include areas where field measurements are scarce, like parts of South America, Africa, and Asia (Ward et al., 2018). At high latitudes, ice and snow dynamics apply a certain control to both river hydrology (Yamazaki et al., 2014) and wave and storm surge dynamics (Vousdoukas et al., 2017). However, such processes are not resolved by the global models used to generate the forcing datasets used in the present study. For these reasons, the present findings should be interpreted with care, especially in northern regions (Couasnon et al., 2020).

The two approaches investigated here provide information only on the potential for CF. The actual CF occurrence depends also on the local topography which can favour or not favour the interaction between the $\mathrm{CF}$ drivers; also, concurrent but not hydrologically interacting storm surges and pluvial or fluvial flooding are relevant as they can e.g. limit the ability to respond to emergency and amplify the impacts that the two hazards would have caused if they occurred in isolation (Martius et al., 2016; Barton et al., 2016; Zscheischler et al., 2019). Moreover, while the two approaches investigated here are supposed to represent different CF mechanisms, separating the CF mechanisms in this way could be misleading, as CF may happen due to a combination of river discharge, local rainfall and associated surface runoff, and high sea level. For example, in July 2019, New Orleans (Louisiana, USA; Vahedifard et al., 2016) was simultaneously threatened by Hurricane Barry causing local rainfall and a storm surge around the coast and by extremely high water discharge from the Mississippi River which lasted from March to July. CF risk assessment at the local scale should be carried out via complex hydrological modelling that can take into account the complex mechanisms causing $\mathrm{CF}$, including storm surges, waves, astronomical tides, and when necessary not only fluvial or pluvial flooding but also their combination.

\section{Conclusions}

We conduct two global-scale potential CF hazard assessments, using either storm surge and precipitation or storm surge and river discharge model data, and we then compare how the choice of precipitation vs. river discharge as a covariate with storm surge affects the results. We find that the two approaches result in similar spatial CF hazard patterns, which tend to deviate as the river catchment size increases. In addition, on average, the deviations between the two assessments are smaller in regions where assessing the actual $\mathrm{CF}$ is more relevant, i.e. where the $\mathrm{CF}$ potential is high.

Due to data scarcity, current large-scale CF assessments rely on approaches and model-based datasets similar to those used here. This study indicates that for these largescale assessments, a precipitation-based CF analysis can provide satisfactory information on the $\mathrm{CF}$ potential in estuaries of small- and medium-sized rivers (catchment smaller than about 5-10 $\times 10^{3} \mathrm{~km}^{2}$ ). Moreover, a precipitation-based $\mathrm{CF}$ analysis allows for assessing the CF hazard arising from the interaction of local coastal rainfall and storm surges where no rivers exist or along the mouths of small rivers often not represented in global river datasets. Naturally, employing river discharge data should always be preferred to using pre- 
cipitation when studying both the large- and local-scale CF in estuaries, when data are available, especially in areas where we detected large differences between the two approaches. The importance of using river discharge data is even greater in estuaries of long rivers. 
Appendix A: Supporting figures

(a) Dependence precipitation-sea

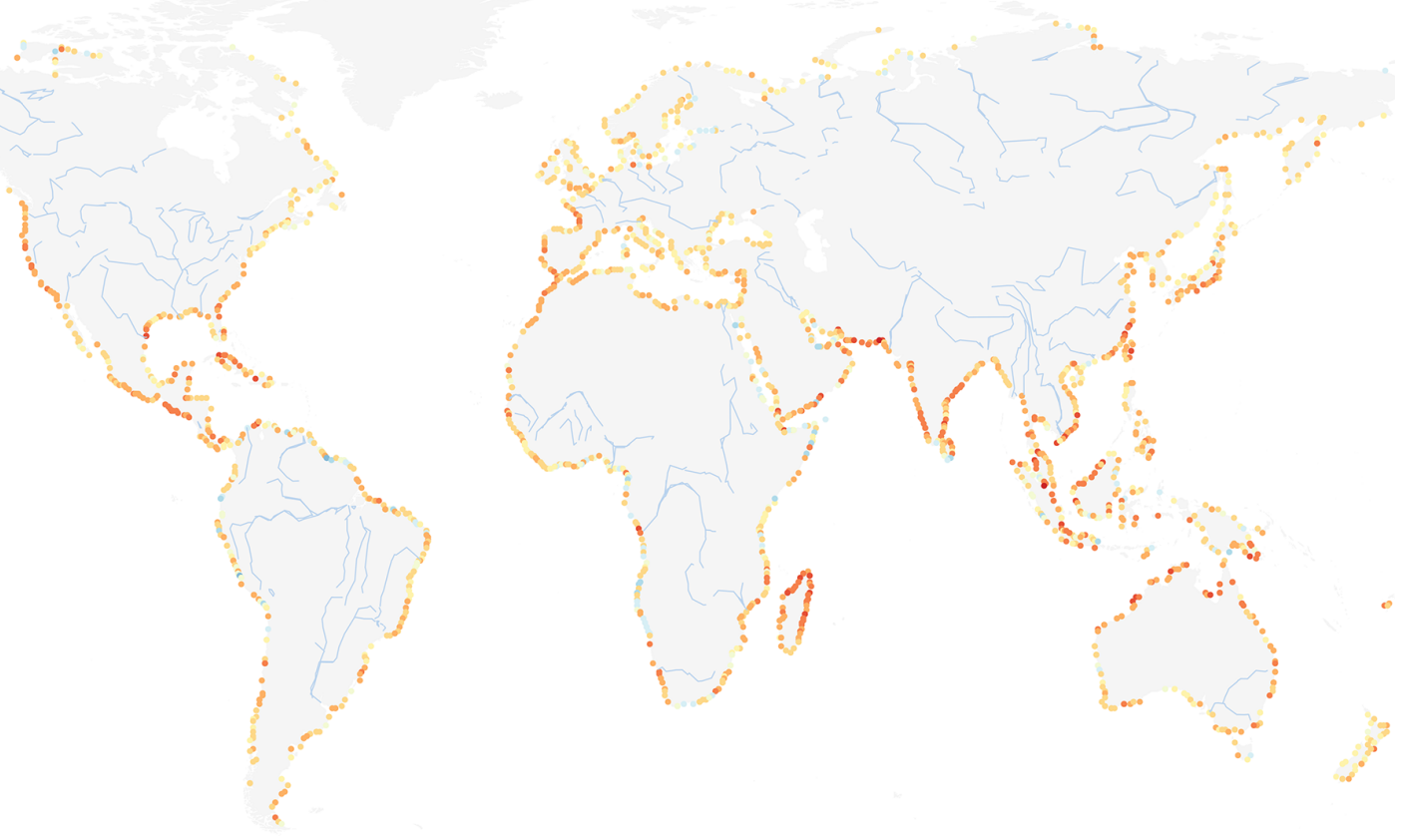

(b) Dependence river-sea
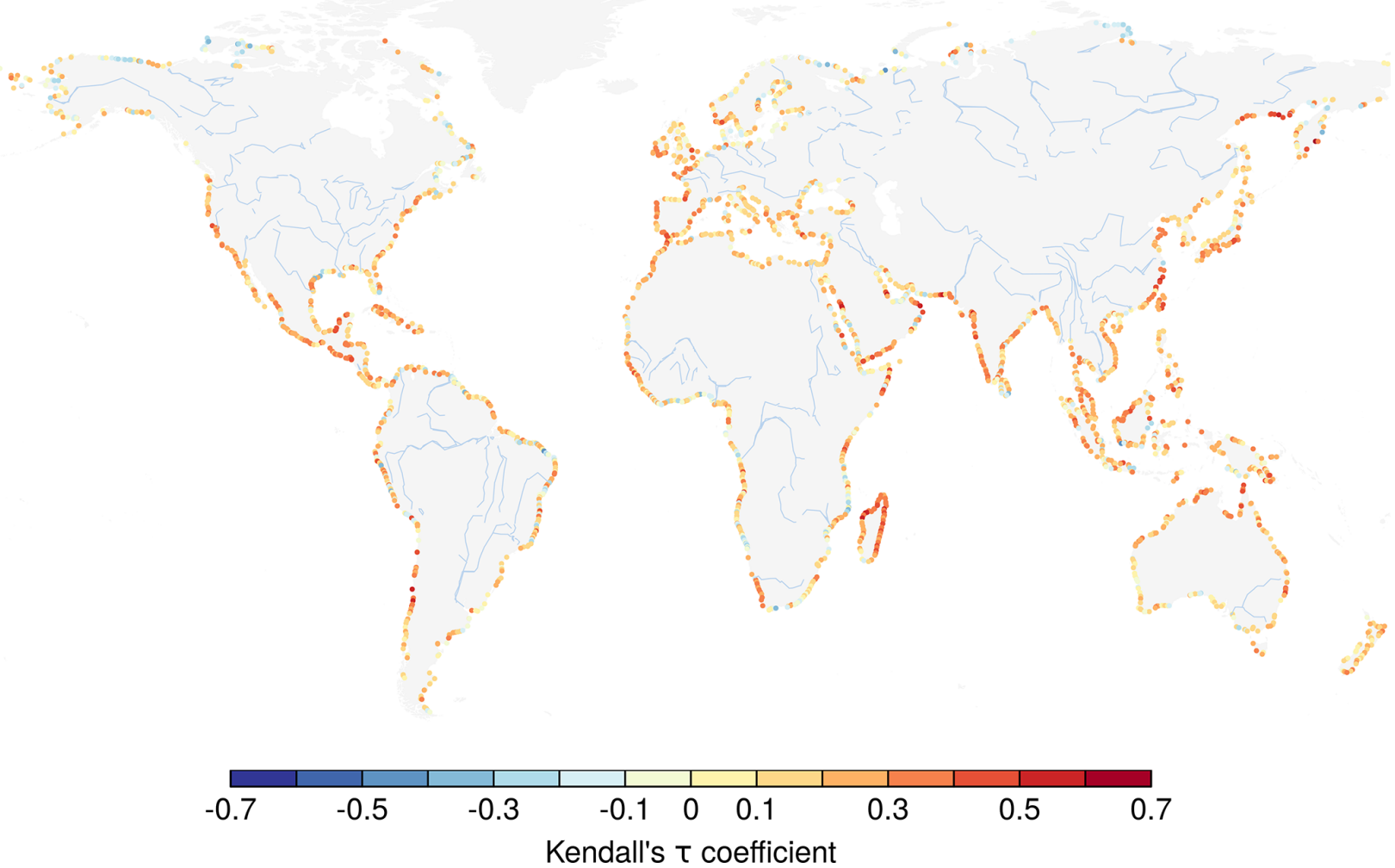

Figure A1. Kendall's $\tau$ correlation associated with the copulas fitted to the selected pairs of (a) precipitation and sea level and (b) river discharge and sea level. 
(a) CF return periods based on precipitation ( $\left.T_{\text {prec }}\right)$

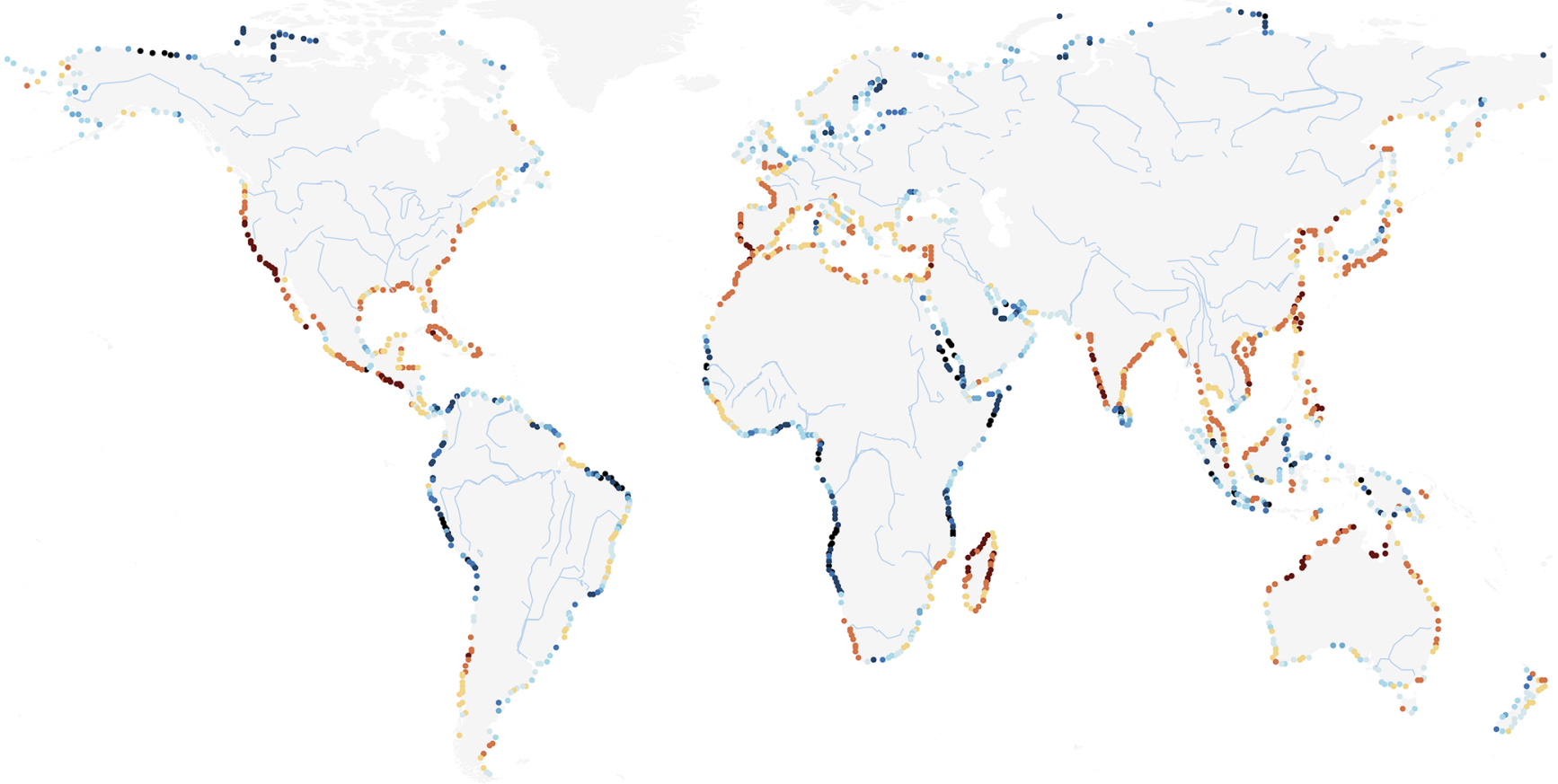

(b) $\mathrm{CF}$ return periods based on river discharges $\left(T_{\text {river }}\right)$
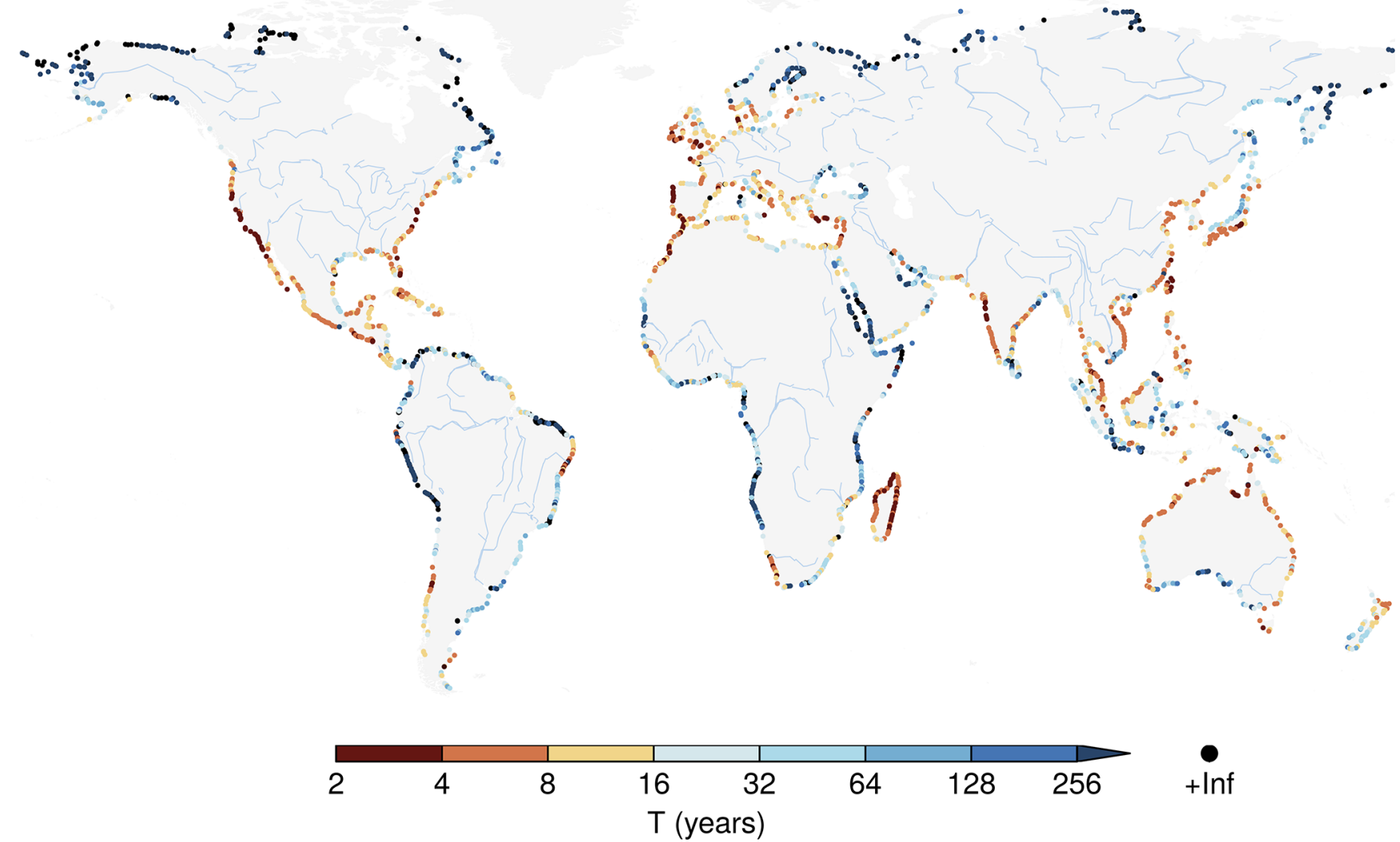

Figure A2. The same as Fig. 1, but the extremes are defined as 2-year return levels. 
(a) Locations with the lowest $\mathrm{CF}$ return periods based on precipitation ( $\left.\mathrm{T}_{\text {prec }}\right)$

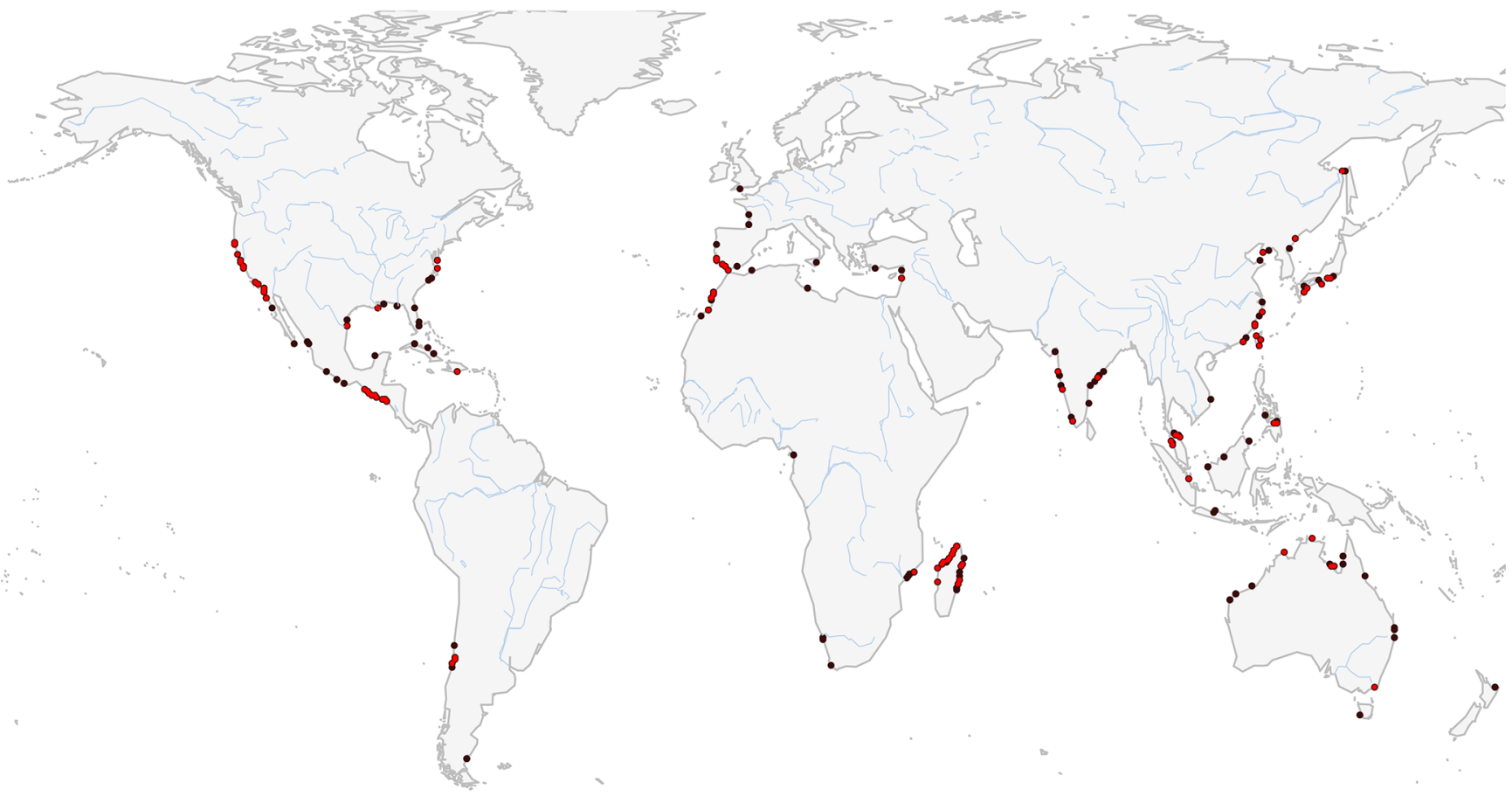

(b) Locations with the lowest $\mathrm{CF}$ return periods based on river discharges $\left(T_{\text {river }}\right)$

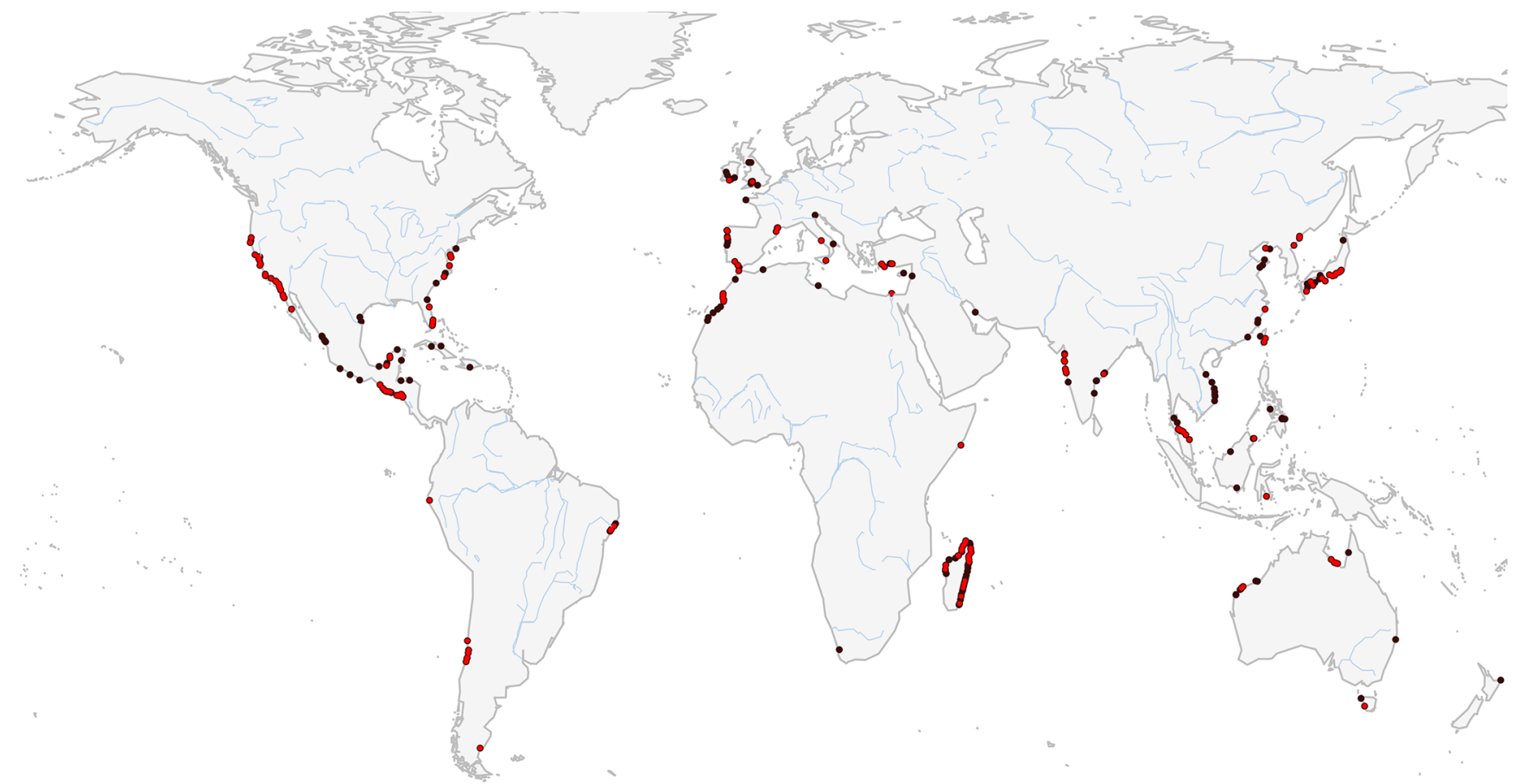

Figure A3. Locations with the lowest potential compound-flooding probability based on precipitation and on river discharge. Locations with return periods below the 10th and 5th percentile are shown in black and red, respectively. The extremes are defined considering 5-year return levels. CF return periods are based on precipitation in (a) and on river discharge in (b). 
(a) Locations with the lowest $\mathrm{CF}$ return periods based on precipitation ( $\left.T_{\text {prec }}\right)$

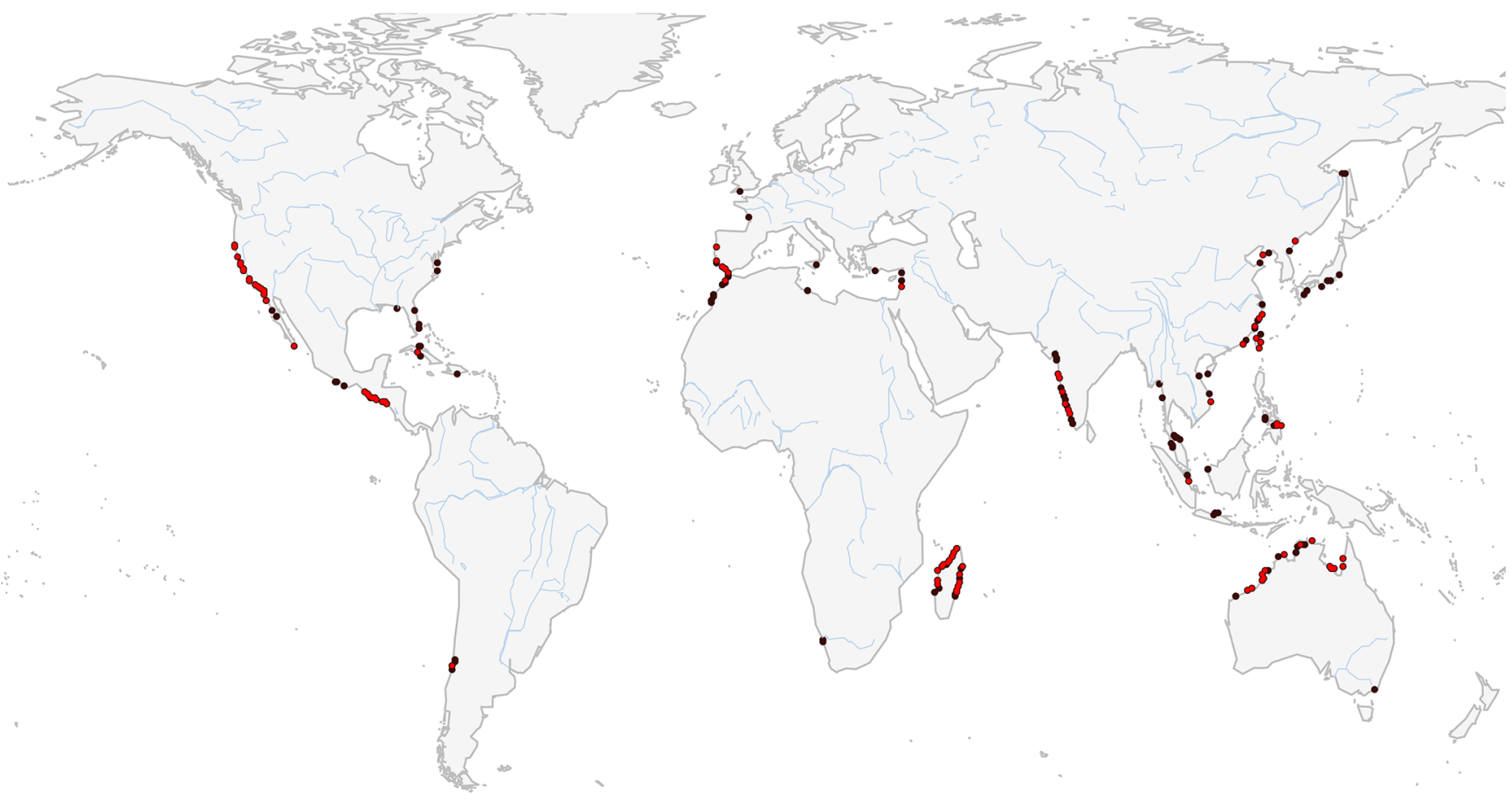

(b) Locations with the lowest CF return periods based on river discharges $\left(T_{\text {river }}\right)$

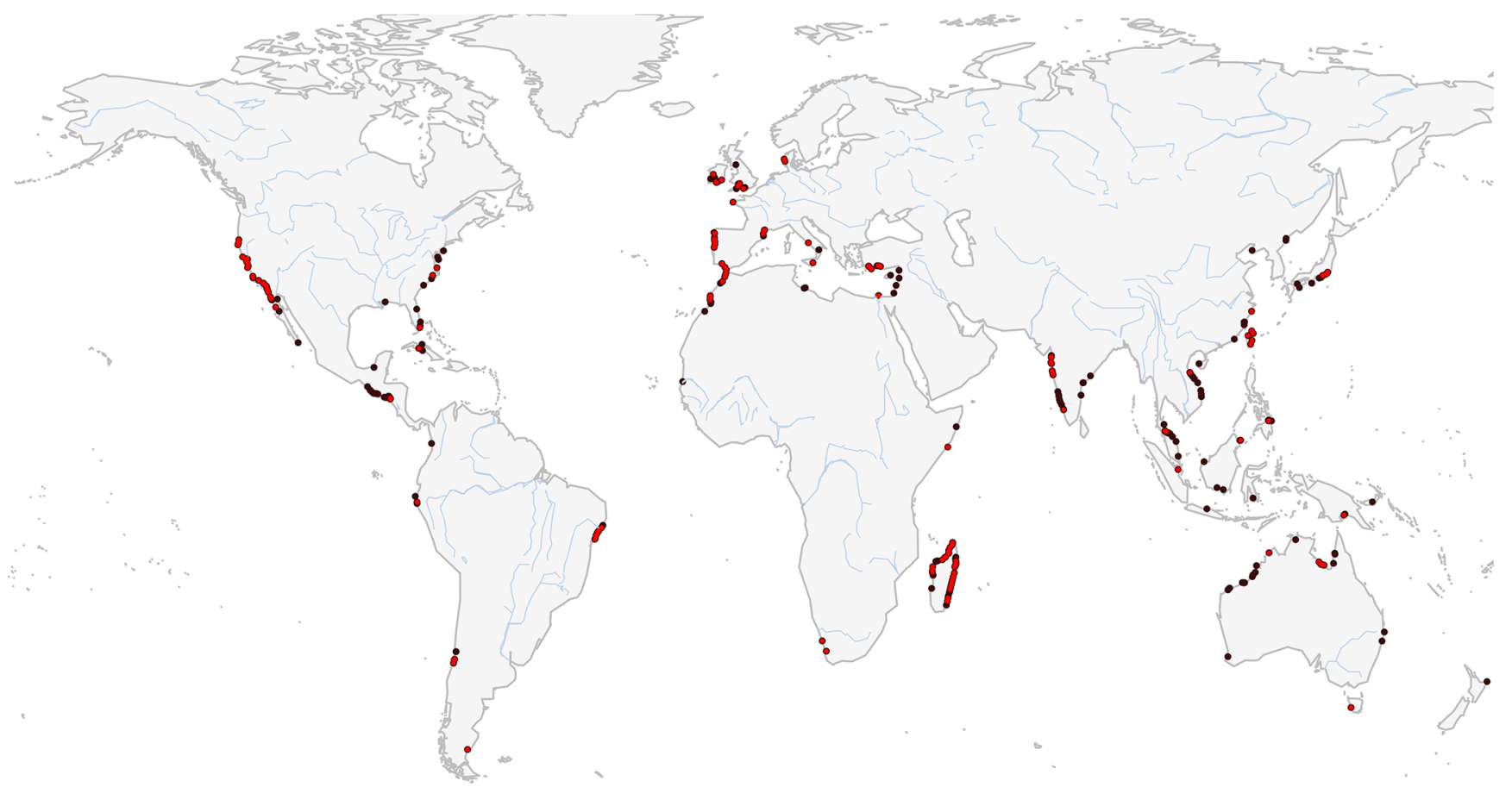

Figure A4. The same as Fig. A3, but the results are based on extremes defined considering 2-year return levels. 
(a) Ratio of CF return periods (statistically incompatible return periods)

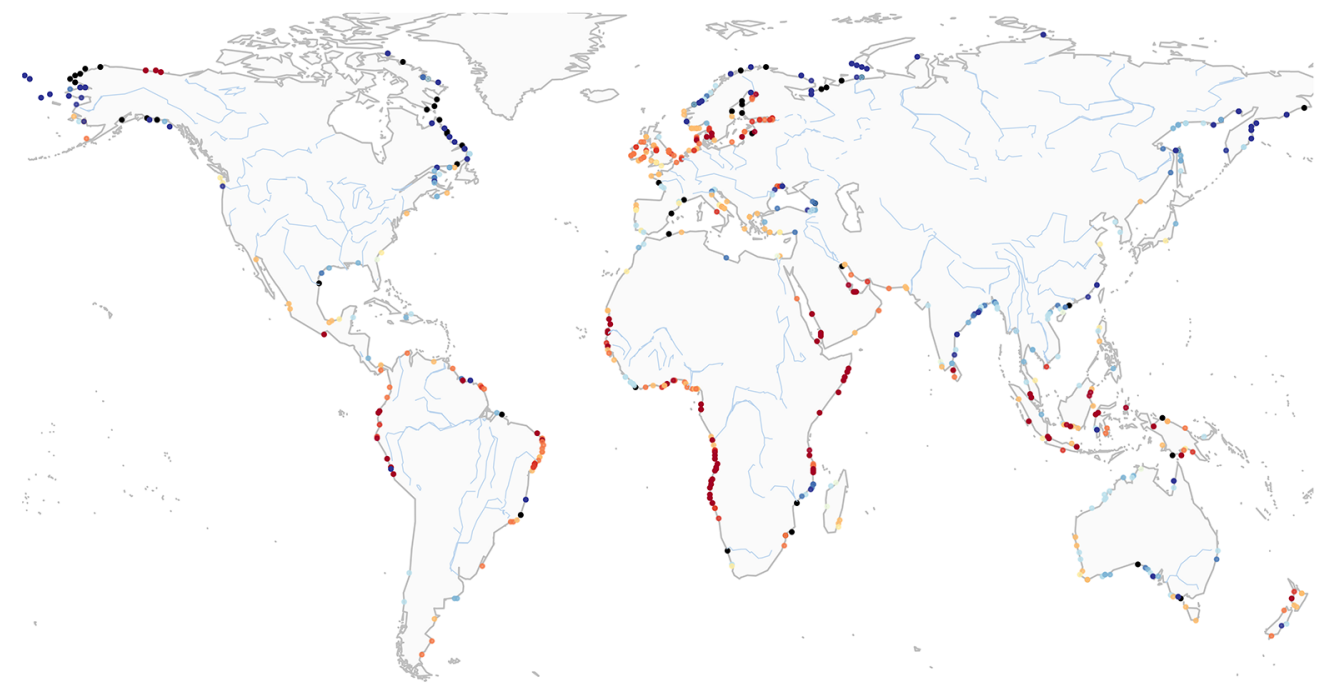

(b) Ratio of CF return periods (statistically compatible return periods)

(c)

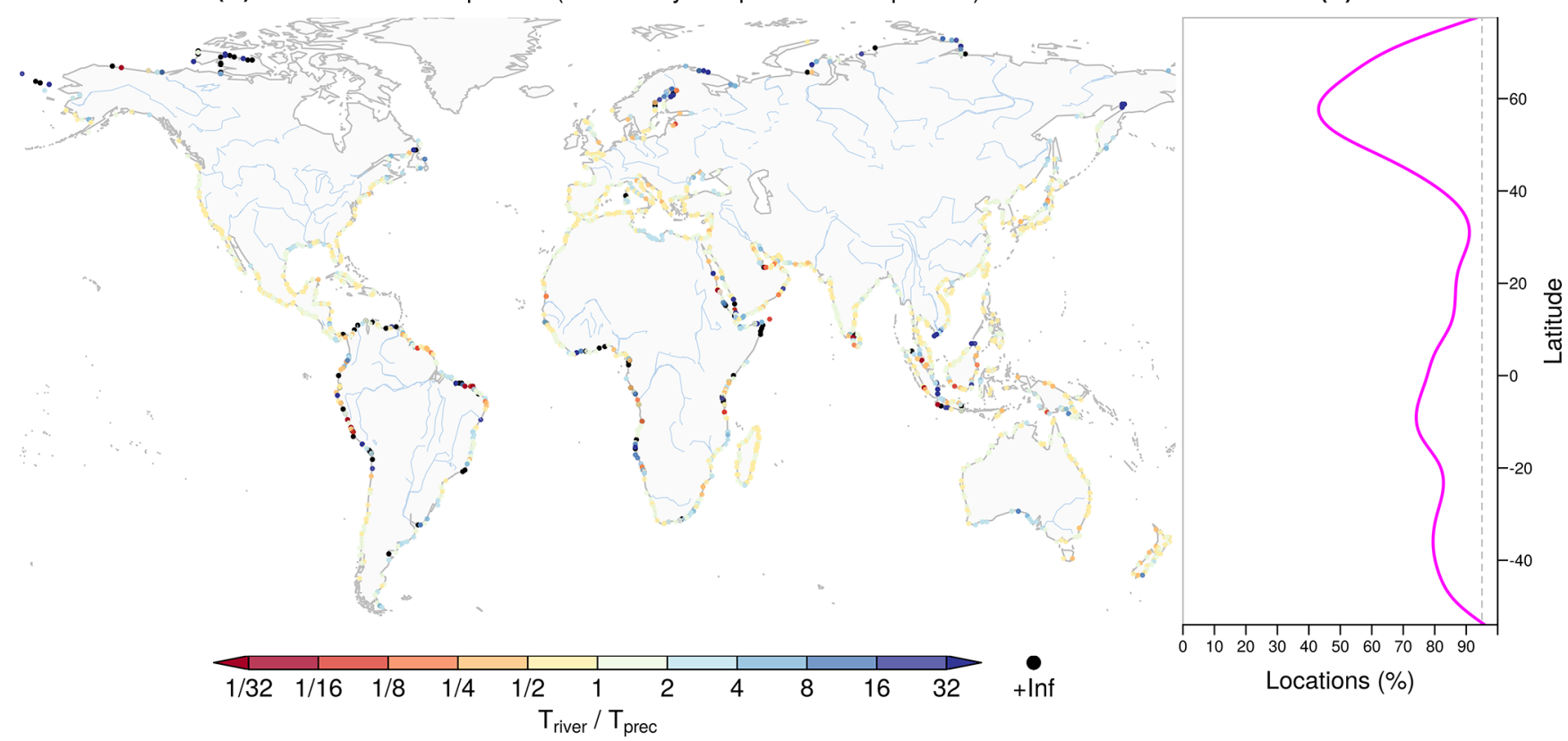

Figure A5. The same as Fig. 2, but the results are based on extremes defined considering 2-year return levels. 
(a) Ratio $T_{\text {river }} / T_{\text {prec }}$

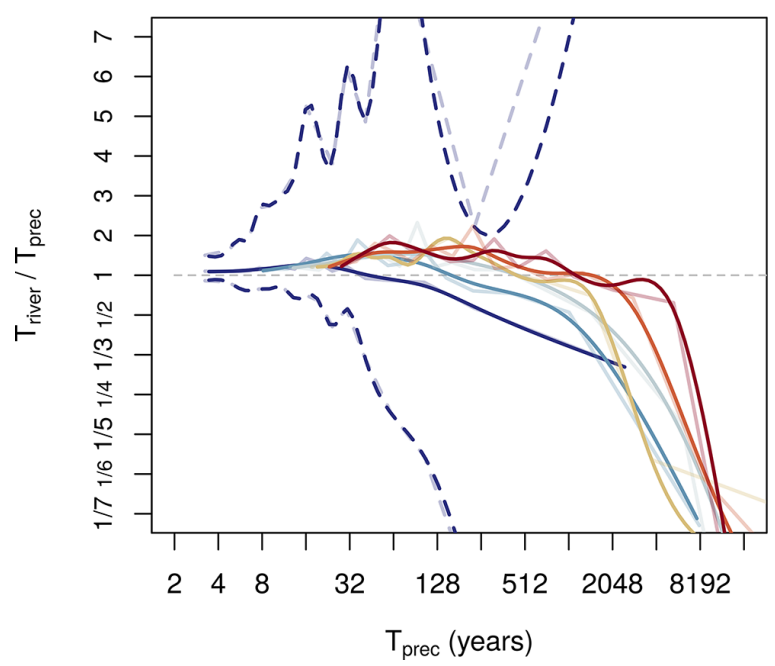

(b) Ratio $T_{\text {river }} / T_{\text {prec }}$

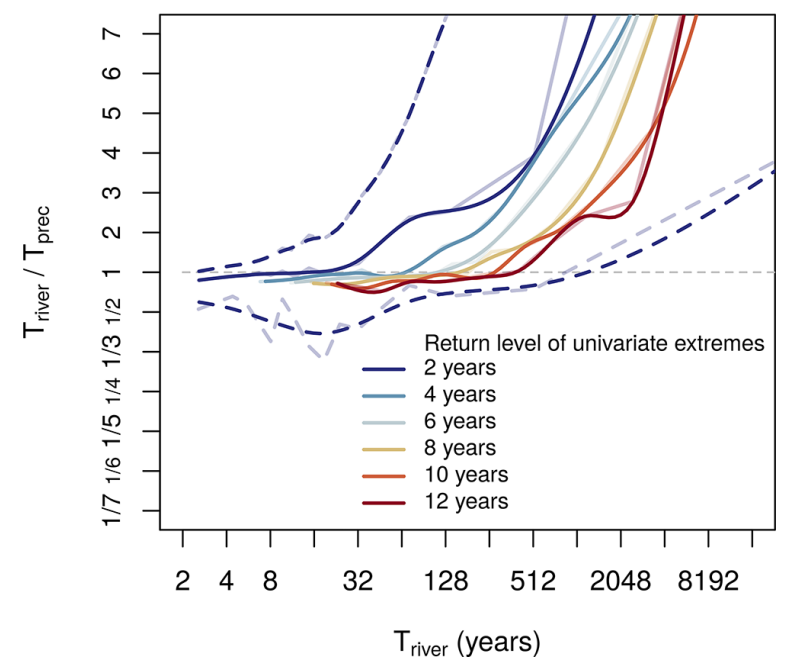

Figure A6. (a) Ratio between the CF return periods based on river discharge $\left(T_{\text {river }}\right)$ and on precipitation $\left(T_{\text {prec }}\right)$ as a function of $T_{\text {prec }}$ (and of the return levels used to define the CF univariate extremes; see legend in $\mathbf{b}$ ). The dashed line is the centred $68 \%$ (16th-84th percentiles) confidence interval of the ratio based on the 2-year return levels. Thick lines are obtained through regressing the investigated statistical values to the natural logarithm of the mean return period of the bins via a spline function. (b) The same as (a), but the ratio is conditioned on $T_{\text {river }}$. As in Fig. 3d of the original paper, a non-linear $y$ axis for values below 1 is employed such that the specular cases, e.g. ratio $r=2$ $\left(T_{\text {river }}=2 \cdot T_{\text {prec }}\right)$ and $r=1 / 2\left(T_{\text {prec }}=2 \cdot T_{\text {river }}\right)$ (see Fig. 3b), appear symmetric with respect to $r=1\left(T_{\text {river }}=T_{\text {prec }}\right)$.

(a) $T_{\text {river }}$ vs. $T_{\text {prec }}$

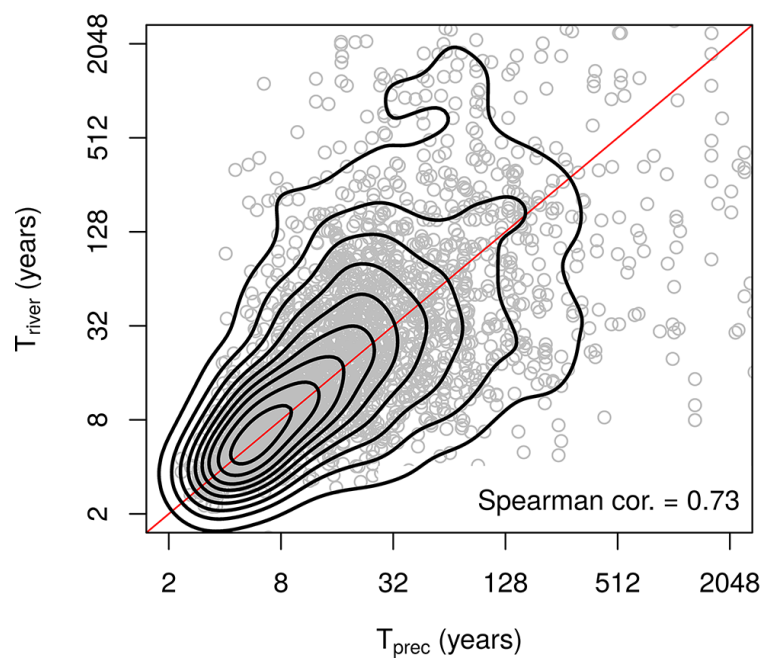

(b) Ratio $T_{\text {river }} / T_{\text {prec }}$

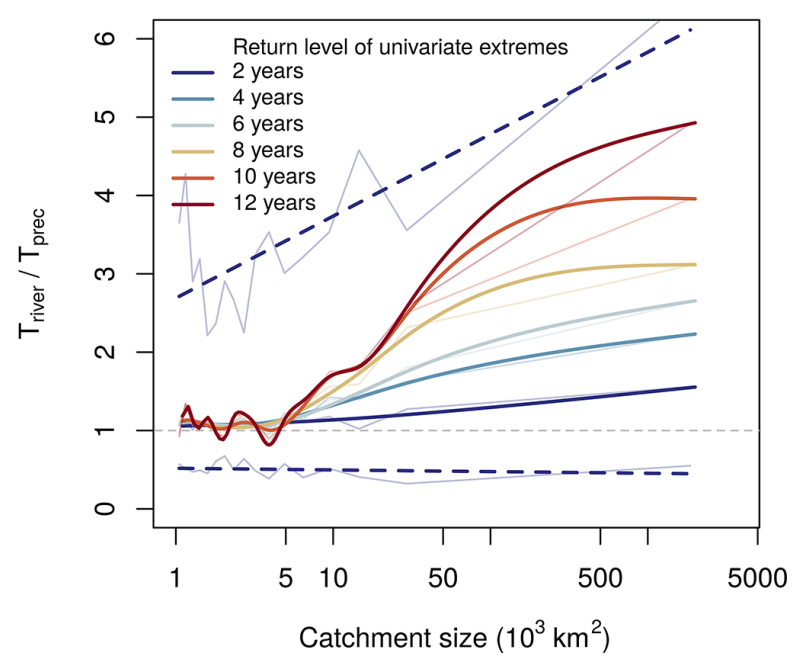

Figure A7. (a) The same as Fig. 3a, but the results are based on extremes defined considering 2-year return levels (the figure is based on Fig. A2). (b) As Fig. 3d but with a linear $y$ axis. 
Data availability. Precipitation data are available on request online (https://ec.europa.eu/jrc/en/publication/mswep-3-hourly-025global-gridded-precipitation-1979-2014 last access: 15 July 2020) (Beck et al., 2017b). Sea level data are available at https://data.jrc. ec.europa.eu/collection/liscoast (last access: 15 July 2020) (Vousdoukas et al., 2018) (further inquiries should be addressed to Michalis I. Vousdoukas). River discharge data obtained from the dataset "Paired time series of daily discharge and storm surge" are available at https://doi.org/10.5281/zenodo.3258007 (Eilander, 2019).

Author contributions. EB initiated the study, carried out the data analysis, and drafted the paper. EB designed the study development with contributions from MIV. EB and MIV worked on the final version of the paper. MIV performed the storm surge runs. All the authors gave conceptual inputs during the data analysis, discussed the results, and commented on the paper.

Competing interests. The authors declare that they have no conflict of interest.

Special issue statement. This article is part of the special issue "Global- and continental-scale risk assessment for natural hazards: methods and practice". It is a result of the European Geosciences Union General Assembly 2018, Vienna, Austria, 8-13 April 2018.

Acknowledgements. Emanuele Bevacqua acknowledges the European COST Action DAMOCLES programme (no. CA17109). Mathieu Vrac acknowledges financial support from the EUPHEME project and CoCliServ project, which are part of ERA4CS, an ERANET initiated by JPI Climate and co-funded by the European Union. The authors would like to thank Lorenzo Mentaschi and Evangelos Voukouvalas, who contributed in the generation of the storm surge time series, and Dirk Eilander for creating and publicly sharing the dataset "Paired time series of daily discharge and storm surge", which was fundamental for the development of this study. Finally, the authors would like to thank two anonymous reviewers for their valuable and constructive comments and suggestions that contributed to improving the paper.

Financial support. This research has been supported by the European Research Council (grant no. 339390) and the European Union (grant no. 690462).

Review statement. This paper was edited by Philip Ward and reviewed by two anonymous referees.

\section{References}

Amrhein, V., Greenland, S., and McShane, B.: Scientists rise up against statistical significance, Nature, 567, 305-307, https://doi.org/10.1038/d41586-019-00857-9, 2019.

Bader, B. and Yan, J.: eva: Extreme Value Analysis with Goodness-of-Fit Testing, $\mathrm{R}$ package version 0.2 .4 , available at: https://mran.microsoft.com/snapshot/2017-08-06/web/ packages/eva/eva.pdf (last access: 16 December 2019), 2016.

Barton, Y., Giannakaki, P., Von Waldow, H., Chevalier, C., Pfahl, S., and Martius, O.: Clustering of regional-scale extreme precipitation events in southern Switzerland, Mon. Weather Rev., 144, 347-369, 2016.

Beck, H. E., van Dijk, A. I. J. M., de Roo, A., Dutra, E., Fink, G., Orth, R., and Schellekens, J.: Global evaluation of runoff from 10 state-of-the-art hydrological models, Hydrol. Earth Syst. Sci., 21, 2881-2903, https://doi.org/10.5194/hess-21-2881-2017, 2017 a.

Beck, H. E., van Dijk, A. I. J. M., Levizzani, V., Schellekens, J., Miralles, D. G., Martens, B., and de Roo, A.: MSWEP: 3hourly $0.25^{\circ}$ global gridded precipitation (1979-2015) by merging gauge, satellite, and reanalysis data, Hydrol. Earth Syst. Sci., 21, 589-615, https://doi.org/10.5194/hess-21-589-2017, 2017b.

Bevacqua, E., Maraun, D., Hobæk Haff, I., Widmann, M., and Vrac, M.: Multivariate statistical modelling of compound events via pair-copula constructions: analysis of floods in Ravenna (Italy), Hydrol. Earth Syst. Sci., 21, 2701-2723, https://doi.org/10.5194/hess-21-2701-2017, 2017.

Bevacqua, E., Maraun, D., Vousdoukas, M. I., Voukouvalas, E., Vrac, M., Mentaschi, L., and Widmann, M.: Higher probability of compound flooding from precipitation and storm surge in Europe under anthropogenic climate change, Sci. Adv., 5, eaaw5531, https://doi.org/10.1126/sciadv.aaw5531, 2019.

Bevacqua, E., Vousdoukas, M., Zappa, G., Hodges, K., Shepherd, T., Maraun, D., Mentaschi, L., and Feyen, L.: Global projections of compound coastal meteorological extremes, preprint: EarthArXiv, https://doi.org/10.31223/osf.io/4x2u8, 2020.

Blöschl, G., Hall, J., Viglione, A., Perdigão, R. A., Parajka, J., Merz, B., Lun, D., Arheimer, B., Aronica, G. T., Bilibashi, A., Boháč, M., Bonacci, O., Borga, M., Čanjevac, I., Castellarin, A., Chirico, G. B., Claps, P., Frolova, N., Ganora, D., Gorbachova, L., Gül, A., Hannaford, J., Harrigan, S., Kireeva, M., Kiss, A., Kjeldsen, T. R., Kohnová, S., Koskela, J. J., Ledvinka, O., Macdonald, N., Mavrova-Guirguinova, M., Mediero, L., Merz, R., Molnar, P., Montanari, A., Murphy, C., Osuch, M., Ovcharuk, V., Radevski, I., Salinas, J. L., Sauquet, E., Šraj, M., Szolgay, J., Volpi, E., Wilson, D., Zaimi, K., and Živković, N.: Changing climate both increases and decreases European river floods, Nature, 573, 108-111, 2019.

Coles, S., Bawa, J., Trenner, L., and Dorazio, P.: An introduction to statistical modeling of extreme values, in: vol. 208, Springer, London, 2001.

Couasnon, A., Eilander, D., Muis, S., Veldkamp, T. I., Haigh, I. D., Wahl, T., Winsemius, H., and Ward, P. J.: Measuring compound flood potential from river discharge and storm surge extremes at the global scale, Nat. Hazards Earth Syst. Sci., 20, 489-504, https://doi.org/10.5194/nhess-20-489-2020, 2020.

Dee, D. P., Uppala, S., Simmons, A., Berrisford, P., Poli, P., Kobayashi, S., Andrae, U., Balmaseda, M., Balsamo, G., Bauer, P., Bechtold, P., Beljaars, A. C. M., van de Berg, L., Bidlot, J., 
Bormann, N., Delsol, C., Dragani, R., Fuentes, M., Geer, A. J., Haimberger, L., Healy, S. B., Hersbach, H., Hólm, E. V., Isaksen, L., Kållberg, P., Köhler, M., Matricardi, M., McNally, A. P., Monge-Sanz, B. M., Morcrette, J.-J., Park, B.-K., Peubey, C., de Rosnay, P., Tavolato, C., Thépaut, J.-N., and Vitart, F.: The ERA-Interim reanalysis: Configuration and performance of the data assimilation system, Q. J. Roy. Meteorol. Soc., 137, 553597, 2011.

Eilander, D.: Paired time series of daily discharge and storm surge, Zenodo, https://doi.org/10.5281/zenodo.3258007, 2019.

Ganguli, P. and Merz, B.: extreme coastal Water Levels exacerbate fluvial flood Hazards in northwestern europe, Scient. Rep., 9, 114, 2019a.

Ganguli, P. and Merz, B.: Trends in Compound Flooding in Northwestern Europe During 1901-2014, Geophys. Res. Lett., 46, 10810-10820, 2019b.

Heffernan, J., Stephenson, A., and Gilleland, E.: Ismev: an introduction to statistical modeling of extreme values, $\mathrm{R}$ package version 1.41, available at: https://CRAN.R-project.org/package= ismev (last access: 16 December 2019), 2016.

Hendry, A., Haigh, I. D., Nicholls, R. J., Winter, H., Neal, R., Wahl, T., Joly-Laugel, A., and Darby, S. E.: Assessing the characteristics and drivers of compound flooding events around the UK coast, Hydrol. Earth Syst. Sci., 23, 3117-3139, https://doi.org/10.5194/hess-23-3117-2019, 2019.

Khanal, S., Ridder, N., de Vries, H., Terink, W., and van den Hurk, B.: Storm Surge and Extreme River Discharge: A Compound Event Analysis Using Ensemble Impact Modeling, Front. Earth Sci., 7, 224, https://doi.org/10.3389/feart.2019.00224, 2019.

Klerk, W.-J., Winsemius, H., van Verseveld, W., Bakker, A., and Diermanse, F.: The co-incidence of storm surges and extreme discharges within the Rhine-Meuse Delta, Environ. Res. Lett., 10, 035005, https://doi.org/10.1088/1748-9326/10/3/035005, 2015.

Kumbier, K., Carvalho, R. C., Vafeidis, A. T., and Woodroffe, C. D.: Investigating compound flooding in an estuary using hydrodynamic modelling: a case study from the Shoalhaven River, Australia, Nat. Hazards Earth Syst. Sci., 18, 463-477, https://doi.org/10.5194/nhess-18-463-2018, 2018.

Manning, C., Widmann, M., Bevacqua, E., Van Loon, A. F., Maraun, D., and Vrac, M.: Soil moisture drought in Europe: a compound event of precipitation and potential evapotranspiration on multiple time scales, J. Hydrometeorol., 19, 1255-1271, 2018.

Manning, C., Widmann, M., Bevacqua, E., Van Loon, A. F., Maraun, D., and Vrac, M.: Increased probability of compound long-duration dry and hot events in Europe during summer (1950-2013), Environ. Res. Lett., 14, 094006, https://doi.org/10.1088/1748-9326/ab23bf, 2019.

Martius, O., Pfahl, S., and Chevalier, C.: A global quantification of compound precipitation and wind extremes, Geophys. Res. Lett., 43, 7709-7717, 2016.

Mentaschi, L., Vousdoukas, M. I., Voukouvalas, E., Dosio, A., and Feyen, L.: Global changes of extreme coastal wave energy fluxes triggered by intensified teleconnection patterns, Geophys. Res. Lett., 44, 2416-2426, 2017.

Moftakhari, H. R., Salvadori, G., AghaKouchak, A., Sanders, B. F., and Matthew, R. A.: Compounding effects of sea level rise and fluvial flooding, P. Natl. Acad. Sci. USA, 114, 9785-9790, 2017.

Muis, S., Verlaan, M., Winsemius, H. C., Aerts, J. C., and Ward, P. J.: A global reanalysis of storm surges and extreme sea levels,
Nat. Commun., 7, 11969, https://doi.org/10.1038/ncomms11969, 2016.

Olbert, A. I., Comer, J., Nash, S., and Hartnett, M.: High-resolution multi-scale modelling of coastal flooding due to tides, storm surges and rivers inflows. A Cork City example, Coast. Eng., 121, 278-296, 2017.

Paprotny, D., Vousdoukas, M. I., Morales-Nápoles, O., Jonkman, S. N., and Feyen, L.: Compound flood potential in Europe, Hydrol. Earth Syst. Sci. Discuss., https://doi.org/10.5194/hess-2018-132, 2018.

Ridder, N., de Vries, H., and Drijfhout, S.: The role of atmospheric rivers in compound events consisting of heavy precipitation and high storm surges along the Dutch coast, Nat. Hazards Earth Syst. Sci., 18, 3311-3326, https://doi.org/10.5194/nhess18-3311-2018, 2018.

Schepsmeier, U., Stoeber, J., Brechmann, E. C., Graeler, B., Nagler, T., and Erhardt, T.: VineCopula: Statistical inference of vine copulas, R package version 2.0.5, availble at: https://cran.r-project. org/web/packages/VineCopula/ (last access: 16 December 2019), 2016.

Vahedifard, F., AghaKouchak, A., and Jafari, N. H.: Compound hazards yield Louisiana flood, Science, 353, 1374, https://doi.org/10.1126/science.aai8579, 2016.

Vandenberghe, S., Verhoest, N., Onof, C., and De Baets, B.: A comparative copula-based bivariate frequency analysis of observed and simulated storm events: A case study on BartlettLewis modeled rainfall, Water Resour. Res., 47, W07529, https://doi.org/10.1029/2009WR008388, 2011.

van den Hurk, B., van Meijgaard, E., de Valk, P., van Heeringen, K.J., and Gooijer, J.: Analysis of a compounding surge and precipitation event in the Netherlands, Environ. Res. Lett., 10, 035001, https://doi.org/10.1088/1748-9326/10/3/035001, 2015.

Vousdoukas, M. I., Mentaschi, L., Voukouvalas, E., Verlaan, M., and Feyen, L.: Extreme sea levels on the rise along Europe's coasts, Earth's Future, 5, 304-323, 2017.

Vousdoukas, M. I., Mentaschi, L., Voukouvalas, E., Verlaan, M., Jevrejeva, S., Jackson, L. P., and Feyen, L.: Global probabilistic projections of extreme sea levels show intensification of coastal flood hazard, Nat. Commun., 9, 2360, https://doi.org/10.1038/s41467-018-04692-w, 2018.

Wahl, T., Jain, S., Bender, J., Meyers, S. D., and Luther, M. E.: Increasing risk of compound flooding from storm surge and rainfall for major US cities, Nat. Clim. Change, 5, 1093-1097, 2015

Ward, P. J., Couasnon, A., Eilander, D., Haigh, I. D., Hendry, A., Muis, S., Veldkamp, T. I., Winsemius, H. C., and Wahl, T.: Dependence between high sea-level and high river discharge increases flood hazard in global deltas and estuaries, Environ. Res. Lett., 13, 084012, https://doi.org/10.1088/17489326/aad400, 2018.

$\mathrm{Wu}, \mathrm{W}$. and Leonard, M.: Impact of ENSO on dependence between extreme rainfall and storm surge, Environ. Res. Lett., 14, 124043, https://doi.org/10.1088/1748-9326/ab59c2, 2019.

Wu, W., McInnes, K., O'grady, J., Hoeke, R., Leonard, M., and Westra, S.: Mapping Dependence Between Extreme Rainfall and Storm Surge, J. Geophys. Res.-Oceans, 123, 2461-2474, 2018.

Yamazaki, D., O’Loughlin, F., Trigg, M. A., Miller, Z. F., Pavelsky, T. M., and Bates, P. D.: Development of the global width database for large rivers, Water Resour. Res., 50, 3467-3480, 2014. 
Zscheischler, J., Westra, S., Hurk, B. J., Seneviratne, S. I., Ward, P. J., Pitman, A., AghaKouchak, A., Bresch, D. N., Leonard, M., Wahl, T., and Zhang, X.: Future climate risk from compound events, Nat. Clim. Change, 8, 469-477, https://doi.org/10.1038/s41558-018-0156-3, 2018.
Zscheischler, J., Martius, O., Westra, S., Bevacqua, E., Raymond, C., Horton, R., van den Hurk, B., AghaKouchak, A., Jézéquel, A., Mahecha, M. D., Maraun, D., Ramos, A. M., Ridder, N., Thiery, W., and Vignotto, E.: A typology of compound weather and climate events, Nat. Rev. Earth Environ., accepted, 2019. 